\title{
1 Rapid divergence and gene flow at high latitudes shape the history of Holarctic
}

\section{2 ground squirrels (Urocitellus)}

4 Bryan S. McLean ${ }^{1,2,3}$, Donavan J. Jackson ${ }^{1,2}$, and Joseph A. Cook ${ }^{1,2}$

$6{ }^{1}$ University of New Mexico Department of Biology, 1 University of New Mexico, MSC03-

7 2020, Albuquerque, NM 87131 USA

$8{ }^{2}$ Division of Mammals, Museum of Southwestern Biology, 1 University of New Mexico,

9 MSC03-2020, Albuquerque, NM 87131 USA

$10{ }^{3}$ Division of Mammals, National Museum of Natural History, Smithsonian Institution,

11 MRC 108, P.O. Box 37012, Washington, DC 20012-7012 USA

\section{Abstract}

15 Across the animal tree of life, the prevalence and evolutionary role(s) of hybridization

16 remain incompletely understood. Rapidly radiating clades can serve as important

17 systems for investigating these issues; however, such groups are often characterized by

18 additional, widespread sources of gene tree discordance (e.g., incomplete lineage

19 sorting). In this paper, we employed a multilocus dataset, Bayesian gene tree inference,

20 and multiple species tree reconstruction methods to infer phylogeny of Holarctic ground

21 squirrels (Urocitellus). We tested phylogenetic hypotheses based on previous

22 morphological, cytological and single-locus datasets, and began to parse the causes of

23 pervasive gene tree discordance that was observed. There is widespread incomplete

24 lineage sorting in Urocitellus, consistent with rapid diversification embedded within the

25 larger radiation of marmotine ground squirrels. We also recovered strong support for 2

26 instances of mitonuclear discord due to ancient hybridization among members of the 
27 high-latitude parryii-richardsonii-elegans clade. These results add to a growing number

28 of documented hybridization events in ground squirrels, suggesting their radiation is a

29 fertile system for understanding the interplay of diversification and hybridization in animal

30 evolution.

31

32 Keywords: incomplete lineage sorting; hybridization; mitonuclear; posterior predictive

33 simulation; radiation; Beringia

34

35 Corresponding Author: Bryan S. McLean, email: bryansmclean@gmail.com

36

37

38

39

40

41

42

43

44

45

46

47

48

49

50

51

52 
55 The importance of hybridization in animal diversification has become a central issue in

56 evolutionary biology. Long known to be a common feature of plant evolution (Arnold

57 2006), it is only recently that hybridization has been recognized as widespread in

58 animals (Mallet 2005). However, a multitude of studies now demonstrate gene flow at

59 various points along the animal speciation continuum (Hedrick 2013, Toews and

60 Brelsford 2012). In mammals specifically, divergence in the face of gene flow has been

61 documented across multiple taxonomic orders (e.g., Evans et al. 2001, Koepfli et al.

62 2015, Melo-Ferreira et al. 2012, Sullivan et al. 2014). Still, our understanding of the true

63 prevalence of hybridization as well as its primary role(s) across the animal Tree of Life

64 remains incomplete.

65

66 Rapidly radiating clades are ideal systems for investigating the interplay of diversification

67 and hybridization. Some have posited that hybridization can drive radiations, occurring

68 early in divergence and serving primarily to transfer adaptive variation (Joyce et al. 2011,

69 Seehausen 2004), while others have viewed hybridization as a byproduct of radiation,

70 when speciation rates simply outpace the evolution of reproductive incompatibilities

71 (Wiens et al. 2006). However, due to short times between speciation events, rapid

72 radiations also carry high probabilities of incomplete lineage sorting (ILS) owing to failure

73 of gene copies to coalesce within genetic lineages (Degnan and Rosenberg 2006,

74 Maddison 1997). Identifying hybridization in the presence of ILS is problematic because

75 both phenomena can result in similar phylogenetic patterns (Holder et al. 2001) as well

76 as in gene tree discordance that is difficult to parse even with large numbers of loci (e.g.,

77 Leache et al. 2014). Moreover, hybridization is often unpredictable in its' extent, being

78 limited to organellar genome flow in some systems (e.g., Good et al. 2015, Melo-Ferreira 
79 et al. 2011) but involving extensive nuclear gene flow in others (e.g., Cui et al. 2013,

80 Martin et al. 2013).

81

82 Squirrels (Family Sciuridae, 58 genera) provide one example of apparently widespread

83 hybridization in a mammal clade. In northern temperate latitudes alone, hybridization has

84 been documented in flying squirrels (Garroway et al. 2010) and tree squirrels (Chavez et

85 al. 2013), but most often in ground-dwelling squirrels of the tribe Marmotini (Hafner and

86 Yates 1983, Kerhoulas et al. 2015, Nadler et al. 1971, Spiridinova et al. 2006, Thompson

87 et al. 2015, Tsvirka et al. 2006). Marmotine ground squirrels represent a rapid, ongoing

88 radiation (Hafner 1984, Zelditch et al. 2015) that consists of approximately 91 species in

8912 genera distributed across North America and Asia (Helgen et al. 2009, Wilson and

90 Reeder 2005). The dynamics of marmotine hybridization have been most thoroughly

91 investigated in Tamias chipmunks, where mtDNA introgression has occurred repeatedly

92 in parapatrically distributed, non-sister species across western North America (Good et

93 al. 2008, Reid et al. 2010, Sullivan et al. 2014). Unfortunately, our understanding of core

94 Marmotini phylogeny remains incomplete, obfuscating the extent to which similar

95 dynamics characterize the remainder of this clade.

97 We reconstructed the evolutionary history of Holarctic ground squirrels (Urocitellus), a

98 clade of medium-bodied, diurnal, and relatively social marmotine ground squirrels

99 distributed across western North America, Beringia, and central Asia (Figs. 1 and 2).

100 Urocitellus species have been the subject of extensive ecological, physiological and life

101 history research over the past several decades (Barnes 1989, Boyer and Barnes 1999,

102 Karels and Boonstra 2000, Murie and Michener 1984); still, a taxonomically

103 comprehensive and well-resolved phylogeny of Urocitellus is lacking. We generated a

104 multilocus dataset for Urocitellus that included all 12 species (and 33 of 36 subspecies) 
105 and used Bayesian gene tree inference as well as 3 species tree reconstruction methods

106 to infer phylogeny and test longstanding phylogenetic hypotheses concerning this high-

107 latitude genus (Section 2.1). We identified gene tree discordance due to both ILS and

108 hybridization, and used posterior predictive simulations to assess consistency of our

109 data with the latter process. We discuss these results in the broader context of the

110 taxonomically widespread hybridization observed to date in ground squirrels, and

111 attempt to identify potential drivers of these phenomena.

112

113 2. Material and Methods

114

115 2.1 Phylogenetic Hypotheses

116

117 We tested 6 hierarchical phylogenetic hypotheses based on previous morphological,

118 cytological and single-locus DNA sequence datasets. Urocitellus has traditionally been

119 divided into "small-eared" and "big-eared" species groups (Figs. 1 and 2), so we first

120 tested if these groups are reciprocally monophyletic (Table 1). The small-eared group

121 consists of 5 small bodied, xeric adapted species distributed in and around the Great

122 Basin, USA (U. washingtoni, U. brunneus, U. canus, U. mollis, U. townsendii). The big-

123 eared group contains 7 species of larger bodied and more mesic adapted squirrels

124 widespread in the Intermountain West, Northern Rockies, Beringia and central Asia ( $U$.

125 armatus, U. beldingi, U. columbianus, U. elegans, U. richardsonii, U. parryii, U.

126 undulatus). We included the Idaho ground squirrel (U. brunneus) in the small-eared

127 group, but note its' previous alliance with the large-eared group based on several

128 morphological characters (Davis 1939, Yensen and Sherman 1997).

129 
130 Systematic relationships within the small-eared species group have been historically

131 problematic. In particular, Townsend's ground squirrel (U. townsendii) has been

132 considered conspecific with Merriam's ground squirrel (U. canus) and the Piute ground

133 squirrel (U. mollis), an assemblage termed the 'townsendii complex' (Howell 1938,

134 Nadler et al. 1982; reviewed by Rickart 1987). These are currently considered 3 distinct

135 species based on chromosomal variation (Cole and Wilson 2009, Nadler et al. 1982,

136 Rickart 1985) but monophyly of this complex has not been established; thus it is unclear

137 whether the morphological similarity of these species is due to convergence or common

138 ancestry. We therefore tested monophyly of the townsendii complex (Table 1).

140 Previous sequence-based analyses of Urocitellus used a single mitochondrial (mtDNA)

141 locus (CYTB; Harrison et al. 2003) and failed to recover reciprocally monophyletic big-

142 eared and small-eared groups as well as a monophyletic townsendii complex. That

143 analysis also recovered multiple instances of species non-monophyly. Specifically,

144 Richardson's and Wyoming ground squirrels (U. richardsonii and U. elegans,

145 respectively) were nested within an Arctic ground squirrel (U. parryii) clade, rendering $U$.

146 elegans polyphyletic and U. parryii paraphyletic with respect to the former two taxa (also

147 see Galbreath et al. 2011). Similarly, in the small-eared group, U. mollis was recovered

148 as paraphyletic with respect to $U$. canus (Harrison et al. 2003). We tested the monophyly

149 of each of these currently recognized species (U. elegans, U. parryii, U. mollis; Table 1)

150 using our multilocus dataset.

151

$152 \quad 2.2$ Sample Selection and Sequencing

153

154 We used 2 sampling approaches based on museum specimens (Appendix A.1). The first

155 was an expanded taxon sampling scheme, wherein 98 Urocitellus and 2 outgroup 
156 marmotines (Ammospermophilus leucurus, Otospermophilus beecheyi) were sequenced

157 for up to 2 mtDNA and 1 nuclear locus (mtDNA CYTB and control region [CTRL]; partial

158 von Willebrand factor [VWF]). The second approach aimed to expand character

159 sampling: 44 of these individuals (including 2 outgroups) were sequenced at 4 additional

160 nuclear loci (breast and ovarian cancer susceptibility 1 [BRCA], beta fibrinogen [FGB],

161 glucosidase, beta, acid [GBA], growth hormone receptor [GHR]; Table A.2). Nuclear loci

162 were chosen based on their utility for resolving rodent relationships at a variety of

163 temporal scales (Adkins et al. 2001, Huchon et al. 1999). Several mtDNA sequences

164 were also obtained from GenBank (Appendix A.1).

165

166 Genomic DNA was extracted from frozen or ethanol-preserved liver or muscle tissues

167 using Omega E.Z.N.A. extraction kits (Omega Bio-tek, Inc.) following manufacturer

168 protocols. Ethanol-preserved samples were rinsed for $12-24$ hours in $\mathrm{ddH}_{2} \mathrm{O}$ under

169 refrigeration prior to extraction. A number of museum skins (ventral skin clips or

170 footpads) were also sampled for one or both mtDNA loci. These were first washed in

$17195 \%$ ethanol (24 hours) and then STE buffer (24 hours) under refrigeration, with regular

172 vortexing every few hours. Extractions proceeded using the same protocols as above.

173 All extracts were quantified on a NanoDrop 2000 (Thermo Fisher Scientific).

175 Standard PCR amplification took place in $25 \mu \mathrm{L}$ reactions using primer combinations

176 given in Table A.1. All sequences were generated using Big Dye Terminator 3.1

177 technology (Applied Biosystems) on an ABI 3130 automated DNA sequencer in the

178 Molecular Biology Facility in the Department of Biology at University of New Mexico.

179 Sequences were manually edited in Sequencher v5.3 (Gene Codes Corp., Michigan,

180 USA) and aligned using MUSCLE v3.7 (Edgar 2004) using default settings on the 
181 CIPRES science gateway (www.phylo.org). Raw sequence assemblies were deposited

182 in GenBank (KX278443-KX278683).

$184 \quad 2.3$ Tests of Selection

186 We used the software Mega v.6.06 (Tamura et al. 2013) to conduct Z-tests of

187 hypotheses of positive selection for each exonic locus in our dataset (CYTB, VWF,

188 BRCA, GBA, GHR; FGB is largely intronic and was omitted from tests). For this test,

189 GBA was trimmed to include only coding regions. The test statistic $(Z)$ was calculated as

190 the difference between nonsynonymous and synonymous substitutions (i.e., $d_{N}-d_{S}$ )

191 divided by the square of combined variances of each type of substitution. Hypothesis

192 tests were conducted in a pairwise manner after first binning sequences by species. The

193 Nei-Gojobori substitution model was employed, 500 bootstrap replicates were used, and

194 statistical significance was assessed at the $p=0.05$ level.

196 2.4 Phylogenetic Analysis

198 Gene tree inference was conducted separately on mtDNA (partitioned by locus) and

199 single nuclear locus datasets in MrBayes v3.2.3 (Ronquist and Huelsenbeck 2003) on

200 CIPRES. Reversible jump MCMC (Huelsenbeck et al. 2004) was used to sample model

201 space, allowing topological inference while incorporating uncertainty in substitution

202 parameters. A gamma distribution with four categories was used to approximate among-

203 site rate variation. Rate priors and other parameters (except topology and branch length)

204 were allowed to vary among mtDNA partitions; default values were used for other priors

205 in all analyses. Times to convergence varied significantly, with MCMC runs of 25 million

206 (mtDNA), 50 million (BRCA, FGB, GHR), or 150 million (GBA, VWF) generations. Proper 
207 mixing was assessed by viewing trace plots in Tracer v1.6.0 (Rambaut et al. 2014), and

208 we required effective sample sizes $>200$ for all estimated parameters. Posterior

209 distributions of gene trees were summarized either as maximum clade credibility (MCC)

210 phylograms (in text) or majority-rule consensus phylograms (Fig. A.1) following removal

211 of a burn-in of the first $20 \%$ of trees using TreeAnnotator v1.8.2.

212

213 Species trees were inferred from the expanded character dataset (42 Urocitellus +

214 outgroups) using 3 different methods. First, we used *BEAST v1.8.1 (Drummond et al.

215 2012), which simultaneously infers gene trees and their encasing species tree in a

216 hierarchical coalescent framework. *BEAST has been shown to have power in species

217 tree inference even if ILS exists (e.g., Lanier et al. 2014). However, "BEAST does not

218 model horizontal transfer as a source of gene tree discord, and results could be

219 misleading if horizontal transfer goes undetected. *BEAST analyses were conducted

220 using all loci and nuclear loci only (5), both via the CIPRES gateway. Analyses were run

221 for 750 million generations, sampling posterior distributions every 2500 generations and

222 assessing proper mixing in Tracer as described above. A burn-in of $50 \%$ of trees was

223 removed and posterior distributions were summarized as MCCs as above.

224

225 The software STAR (Liu et al. 2009) and MP-EST (Liu et al. 2010) were also used to

226 infer species trees from the expanded character dataset. Inputs for both are gene trees

227 (which are assumed to be known without error). Of the variety of summary species tree

228 methods recently developed, 2 broad categories exist: those that use only gene tree

229 topologies and those that also use the coalescence times inferred on gene trees

230 (DeGiorgio and Degnan 2014). STAR and MP-EST are in the former category (i.e., use

231 topologies). Briefly, STAR estimates species trees based on a distance matrix describing

232 the average rank coalescences of all possible taxon pairs (Liu et al. 2009), while MP- 
233 EST estimates species trees by maximizing a pseudo-likelihood function which takes

234 into account all possible rooted taxon triples in gene trees that could be encoded by a

235 species tree (Liu et al. 2010).

236

237 We chose STAR and MP-EST for 2 reasons. First, because they do not model ploidy,

238 the influence of mtDNA relative to nuclear loci is reduced. It has been shown that mtDNA

239 can have disproportionately strong influence on species trees in *BEAST due to its high

240 variability and because assumptions of lower ploidy (which is modeled by *BEAST) are

241 not always met (Jockusch et al. 2015). This is especially true in organisms with female-

242 biased sex ratios and/or high male migration, such as occurs in Urocitellus (Byrom and

243 Krebs 1999, Karels and Boonstra 2000). Second, and relatedly, we used these methods

244 because both may be sensitive to possible instances of mtDNA introgression, which has

245 been commonly documented in ground squirrels. We note that introgression violates the

246 assumptions of all 3 methods used here; however, confident identification of

247 introgressed loci is not always possible at shallow phylogenetic levels or when ILS is

248 pervasive. STAR and MP-EST may therefore decrease the effects of such events if they

249 have occurred (Liu et al. 2010).

250

251 Most coalescent-based summary methods (including STAR and MP-EST) assume gene

252 trees are known without error, which is rarely the case empirically. Bootstrapping

253 approaches aim to incorporate gene tree uncertainty into species tree estimates (Seo

254 2008); however, using the uncertainty from Bayesian posterior distributions, where gene

255 trees are represented in approximate proportion to their likelihood, is a better approach

256 (Liu et al. 2009). This method may be intractable with very large numbers of loci (due to

257 time required for Bayesian gene tree analysis), but it is a reasonable alternative to

258 bootstrapping using smaller numbers of loci. To accomplish this, we used custom scripts 
259 in R (R Core Team 2015) to randomly sample 1000 trees from each gene tree posterior

260 from MrBayes runs after removing $20 \%$ burn-in. We ran both STAR and MP-EST for

2611000 iterations, each time drawing a single tree from each of the randomly

262 downsampled gene tree distributions without replacement (thus inputs for every iteration

263 of the species tree reconstruction methods contained 6 randomly sampled gene trees, 1

264 per locus). We summarized the results of both analyses (total of 1000 species tree

265 reconstructions each) as MCC cladograms in TreeAnnotator, and performed the routine

2663 separate times to ensure congruence.

267

$268 \quad 2.5$ Multidimensional Scaling

269

270 To compare and visualize variation in individual gene tree distributions, we used the

271 Tree Set Visualization package (Tree Set Vis; Hillis et al. 2005) in Mesquite v3.03

272 (Maddison and Maddison 2015). Tree Set Vis performs multidimensional scaling on a

273 pairwise matrix of Robinson-Foulds distances among topologies. Analyses were

274 conducted on 500 trees selected randomly from the 6 MrBayes posterior distributions

275 (mtDNA + nuclear loci; $N=3000$ trees total), and all were run until the stress function

276 stabilized. We repeated each analysis 3 times to ensure congruence.

277

2782.6 Haplotype Network

279

280 Upon identifying possible instances of mitonuclear discord in Urocitellus, we assembled

281 an extended CYTB dataset based the dataset generated in this study combined with

282 additional published and unpublished sequences (Appendix A.1). We did this to visualize

283 in greater detail the distribution of haplotypic diversity for all subspecies of $U$. parryii, $U$.

284 richardsonii and $U$. elegans, as well as just those taxa involved in putative hybridization 
285 events (i.e., U. elegans elegans, U. richardsonii, U. parryii parryii, and U. p. kennicottii).

286 We computed both haplotype networks using the package ape (Paradis et al. 2013) in R.

287 Default settings were used for all parameters; the default distance parameter is the

288 uncorrected distance among sequences under an infinite-sites model.

2.7 Hypothesis Tests

292 We tested the 6 phylogenetic hypothesis referenced above (Section 2.1, Table 1) using

293 nodal support values as a significance criterion. We considered nodal support (posterior

294 probabilities [PP], or "bootstrap" values in the case of STAR and MP-EST) greater than

295 or equal to 0.95 to constitute support for a particular hypothesis; positive or negative

296 results of all tests are reported relative to this threshold.

298 However, there are two potential issues with this approach. First, although 0.95 PP is

299 commonly considered high nodal support, PP is not directly interpretable in a frequentist

300 framework (i.e., recovering a clade with 0.95 PP support is not statistically equivalent to

301 rejecting a hypothesis of non-monophyly under a p-value of 0.05$)$. Moreover, this

302 approach can lead to inflated Type I error rates (Alfaro and Holder 2006). We maintain

303 the $\mathrm{PP}=0.95$ threshold but also refer readers to actual PP or nodal support values.

305 Second, PP from *BEAST and support values from our STAR and MP-EST bootstrap

306 procedure are not directly comparable. The same would apply to comparisons of PP and

307 traditional (nucleotide site) bootstrapping, although studies have shown that bootstrap

308 proportions and PP sometimes have relatively high correlation (Alfaro et al. 2003).

309 However, we note that support values for STAR/MP-EST summary trees provide a

310 measure of clade support that incorporates uncertainty in gene tree distributions and 
311 model parameters, and thus remain more directly interpretable than support values

312 generated using nucleotide and/or locus bootstrapping.

313

$314 \quad$ 2.8 Posterior Predictive Checking

315

316 Following identification of putative mitonuclear discord in Urocitellus, we assessed this

317 possibility more rigorously using the posterior predictive method of Joly et al. (2009).

318 That method (implemented as JML; Joly 2012) compares genetic distances observed

319 between taxon pairs with the minimum genetic distances found from simulation on a set

320 of species trees, the latter of which have been inferred under the coalescent with no

321 migration (e.g., in *BEAST). If empirical genetic distances are significantly lower than

322 those from simulations (i.e., if they are lower than expected based on the time since

323 speciation and given ILS), a hypothesis of discordance due to ILS is rejected, supporting

324 hybridization as a potential cause of gene tree discordance.

325

326 We performed posterior predictive checks using the CYTB expanded taxon dataset

327 described previously (Section 2.2). Although the CTRL dataset should also encode a

328 signature of mtDNA introgression, it has been shown that JML has reduced power to

329 distinguish hybridization from ILS as sequence length decreases (Joly et al. 2009).

330 Given that property, we also removed 4 samples from the CYTB dataset with only partial

331 sequences (representing U. canus canus and U. c vigilis). We used species tree files

332 generated by *BEAST from the expanded character dataset (mtDNA + nuclear) as input

333 for JML, removing a burn-in of $50 \%$ of trees as described previously. We employed a

334 heredity scalar of 0.5 , a GTR model of sequence evolution, and mean values for

335 sequence parameters (base frequencies, rate matrix, and mutation rate) extracted from

336 original *BEAST .log files. We ran a second JML analysis using median values for the 
337 above parameters to ensure consistency. Default values were used for all other input

338 parameters. We ran simulations on 10000 species trees and assessed significance at

339 the $p=0.1$ level (the default setting).

340

341 3. Results

342

343 3.1 Gene Tree Concordance and Discordance in Urocitellus

344

345 The partitioned mtDNA dataset with extended taxon sampling yielded a robustly

346 supported tree (Fig. 3). The majority of nodes received $>0.95 \mathrm{PP}$, including all basal

347 nodes except 3 (i.e., those depicting interspecies relationships), which represents an

348 improvement on single mtDNA gene analyses (Harrison et al. 2003). Monophyly of the

349 big-eared group is strongly supported while monophyly of the small-eared group is not

350 (Table 1), and the latter is true whether or not $U$. brunneus is included in the small-eared

351 group. The mtDNA topology also failed to support monophyly of the townsendii complex.

352 All 3 instances of species mtDNA non-monophyly encountered previously (Galbreath et

353 al. 2011, Harrison et al. 2003) were also recovered in our tree (Fig. 3, Table 1).

354 Specifically, U. mollis is recovered as paraphyletic with respect to $U$. canus, and $U$.

355 richardsonii and $U$. elegans elegans are both nested within an Arctic ground squirrel $(U$.

356 parryii) clade, rendering the latter 2 taxa non-monophyletic. We note that the 2 remaining

357 subspecies of U. elegans (U. e. aureus + U. e. nevadensis) are not nested within $U$.

358 parryii, but positioned basal to it.

360 The VWF tree with expanded taxon sampling failed to support a big-eared clade or a

361 small-eared clade at 0.95 PP (Fig. 4, Table 1); however, both groups were recovered

362 with >0.80 PP. Support for a monophyletic townsendii complex was poor, with strong 
363 support (>0.95 PP) instead obtained for the inclusion of $U$. washingtoni within this group.

364 As expected, the VWF tree differs from mtDNA in overall resolution; 7 of 12 Urocitellus

365 species are recovered as non-monophyletic in VWF. Interestingly, however, U. parryii

366 and $U$. elegans are not among them, although $U$. mollis is (Table 1).

368 VWF and the 4 additional nuclear loci analyzed herein had distinct mutational profiles,

369 including differences in mutation rate and patterns of among-site variation (Table A.2).

370 Still, no nuclear locus strongly supported monophyly of big-eared or small-eared groups

371 or of the townsendii complex (Table 1, Fig. A.1). Multidimensional scaling of Robinson-

372 Foulds distances in Tree Set Vis revealed that posterior distributions of inferred gene

373 trees (mtDNA + 5 nuclear) were completely non-overlapping in tree space (Fig. 5). This

374 inability of multiple independent markers to track deep divergences is consistent with ILS

375 as a result of rapid diversification, which also characterizes the tribe Marmotini as a

376 whole (Hafner 1984, Zelditch et al. 2015). In such situations, many loci are expected to

377 have low probabilities of coalescence between speciation events (Degnan and

378 Rosenberg 2006).

379

380 Conversely, single nuclear loci appeared to support robust tests of the 3 hypotheses of

381 species monophyly (U. elegans, U. parryii, U. mollis). This is not surprising because, if

382 radiations are old enough, sufficient variation may be accumulated to discriminate

383 species despite the fact that ILS obscures deeper relationships. Monophyly of U. parryii

384 and $U$. elegans was supported by 4 of 5 nuclear loci each (Table 1, Fig. A.1), providing

385 strong evidence that both are valid species, concordant with morphological and

386 cytological assessments as well as current taxonomic arrangements (Howell 1938,

387 Nadler et al. 1984, Robinson and Hoffmann 1975). However, unlike in U. parryii and U.

388 elegans, no nuclear loci support $U$. mollis monophyly (Table 1, Figs. 4 and A.1). 
390 All tests of positive selection in coding loci (CYTB, VWF, BRCA, GBA, GHR) were

391 negative at the $p=0.05$ level (Appendix A.2). Thus, recent episodes of selection are not

392 supported as contributors to gene tree discordance among these particular loci.

\section{$394 \quad 3.2$ Species Tree Reconstructions}

396 Despite low phylogenetic resolution in individual loci, we recovered stronger support for

397 interspecies relationships using 3 species tree reconstruction methods based on the 398 expanded character dataset. When all loci (mtDNA + nuclear) were included, monophyly

399 of a big-eared group was consistently supported at 0.95 PP, whereas monophyly of a

400 small-eared group was supported only in *BEAST analyses (Fig. 6, Table 1). Support for

401 monophyly of the townsendii complex was supported by 2 of 3 methods ( ${ }^{*}$ BEAST and

402 STAR). Conversely, when only nuclear loci were included, species trees failed to support

403 any of these hypotheses at the 0.95 level except for in one instance (small-eared

404 monophyly was supported by *BEAST). Nevertheless, we note that monophyly of the

405 big-eared group, small-eared group, and townsendii complex as traditionally defined

406 were each supported at $>0.75$ across methods and datasets (Fig. 6).

408 We found general topological correspondence among species trees and datasets,

409 despite some variation in nodal support (Fig. 6). Inclusion of mtDNA increased support

410 for hypotheses across species tree reconstruction methods, and impacted topology only

411 minimally. We initially predicted that effects of mtDNA inclusion would be more

412 significant, as the mtDNA tree differs from nuclear gene trees and the former marker can

413 have disproportionate influence in *BEAST due to higher variability and/or violated

414 assumptions related to its lower ploidy (e.g., Jockusch et al. 2015). On the contrary, 
415 *BEAST trees using all loci versus nuclear loci were topologically identical and, although

416 nodal support differed, there were no consistent trends in these differences. Conversely,

417 STAR and MP-EST produced topologies that differed by 1 branch each among datasets

418 (U. undulatus in STAR, U. mollis in MP-EST), suggesting greater but still subtle influence

419 of mtDNA in those methods.

420

421 Relationships among small-eared species were generally better resolved than among

422 big-eared species (Fig. 6). Poor support for big-eared species relationships is driven by

423 instability in placement of $U$. armatus, $U$. beldingi, and $U$. columbianus. A sister

424 relationship of $U$. armatus and $U$. beldingi (parapatric species in western North America;

425 Fig. 1) was strongly supported by mtDNA (Fig. 3) but not recovered in any species tree.

426 Instead, the most common (but weakly supported) relationship was $U$. beldingi as sister

427 to $U$. columbianus. The Columbian ground squirrel (U. columbianus) has sometimes

428 been considered sister to the Arctic ground squirrel (U. parryii) based on morphological

429 (Howell 1938) and chromosomal (Nadler 1966, Nadler et al. 1974, Nadler et al. 1984)

430 data, but we found no support for that arrangement, consistent with previous work

431 (Harrison et al. 2003, Robinson and Hoffmann 1975). Finally, placement of the long-

432 tailed ground squirrel (U. undulatus) is inconsistent; this species is exclusively Palearctic

433 in distribution and may represent a long branch that is difficult to place phylogenetically.

4353.3 Support for Hybridization

436

437 Based on phylogenetic inferences (summarized in Table 1), we hypothesize that 438 mitonuclear discord in the parryii-richardsonii-elegans (PRE) clade is the result of

439 hybridization leading to mtDNA capture. This is based on the fact that a majority of

440 nuclear loci support monophyly of $U$. elegans and $U$. parryii, and lineage sorting in 
441 mtDNA is expected to occur faster than in nuclear loci based on lower ploidy and higher

442 mutation rate (e.g., Table A.2). However, a single hybridization event between U. parryii

443 and the most recent common ancestor of $U$. richardsonii and $U$. elegans (likely sister

444 species, see 3.2 above) is unsupported because remaining subspecies of $U$. elegans ( $U$.

445 e. aureus + U. e. nevadensis) carry ancestral, non-introgressed haplotypes (Fig. 3). We

446 therefore propose that 2 ancient, sequential hybridization events occurred in the PRE

447 clade, first from high arctic populations of U. parryii (U. p. kennicottii or U. p. parryii) to a

448 single subspecies of $U$. elegans (U. e. elegans), and second with the latter taxon acting

449 as a mitochondrial vector, transmitting a recently acquired U. parryii mtDNA genome to

450 its sister species U. richardsonii.

451

452 This sequential hybridization scenario is supported by the CYTB haplotype network (Fig.

453 7), calculated using specimens of the 4 relevant taxa (Table A.1), as well as by genetic

454 distances between those taxa returned from JML analyses (Table 2, and below).

455 However, distances between U. parryii-U. e. elegans and U. parryii-U. richardsonii differ

456 only minimally, and the directionality of gene flow we propose must be interpreted with

457 caution until additional nuclear data are available to resolve species phylogeny. The

458 haplotype network for all PRE taxa is also ambiguous with respect to the most

459 parsimonious scenario of mtDNA gene flow (Fig. A.2). Thus, we cannot at present reject

460 an alternate scenario of introgression (U. parryii -> U. richardsonii -> U. elegans), nor the

461 possibility that this phylogroup carries an ancestral $U$. richardsonii mtDNA genome, such

462 that $U$. richardsonii hybridized with U. parryii (ancient) and U. elegans (more recently).

464 Results of posterior predictive checking in JML support the assertion that mitonuclear

465 discordance in Urocitellus is due to a process other than ILS. JML runs recovered 5

466 interspecific comparisons (of 91 total) with observed mtDNA distances significantly lower 
467 than expected under a coalescent model (Table 2). Notably, these include all 3 pairwise

468 species comparisons in the PRE clade. Inspection of JML output confirmed that these

469 results are driven solely by comparisons among $U$. richardsonii, $U$. parryii parryii, $U$.

470 parryii kennicottii, and U. elegans elegans, consistent with the hybridization scenario we

471 outline above. Table 2 also lists the number of significant comparisons at the subspecific

472 level as a percentage of all such possible comparisons, highlighting the taxonomically

473 isolated nature of introgression.

474

475 In addition to the PRE clade, JML recovered comparisons between $U$. beldingi and each

476 of $U$. mollis and $U$. canus as deviating from a strict coalescent model. This is interesting

477 because no evidence for mtDNA introgression exists in these taxa (Fig. 3), and minimum

478 genetic distances are much higher than within the PRE clade (Table 2). Moreover, no

479 comparisons were significant at the $p=0.05$ level, which possibly is reflective of power

480 issues. We return to both of these points in the Discussion.

481

$482 \quad 3.4$ New phylogeographic insights in the Arctic ground squirrel

483

484 The expanded taxon mtDNA dataset included complete taxon sampling at the

485 subspecific level for U. parryii, including 2 subspecies never before sequenced (U. $p$.

486 parryii and U. p. stejnegeri). We recovered 4 major mtDNA clades as observed by

487 previous workers (Eddingsaas et al. 2004, Galbreath et al. 2011; Figs. 3 and 8): Arctic,

488 Southeast (SE Alaska, NW Canada), Southwest (SW Alaska, including Alaskan

489 Peninsula and Aleutian Arc), and Beringian (Siberia, Seward Peninsula, interior Alaska).

490 Our reconstructions placed U. p. parryii within the Arctic clade, sister to U. p. kennicottii,

491 and placed U. p. stegnejeri (Kamchatka, Russia) in the Southwest clade. These results 
492 demonstrate that 2 distinct $U$. parryii mtDNA clades currently have amphiberingian

493 distributions.

494

495 4. Discussion

496

497 4.1 The Complex Genomic History of Urocitellus

499 To date, a comprehensive and well-resolved phylogeny of Urocitellus has proven

500 elusive. This is despite extensive research using chromosomal and karyotypic (Nadler

501 1966, Nadler et al. 1971, Nadler et al. 1984, Rickart 1985), protein electrophoretic

502 (Nadler and Hoffmann 1977, Nadler et al. 1974) and morphological (Robinson and

503 Hoffmann 1975) data. While these previous studies greatly clarified issues of

504 systematics and biogeography, the lack of a model-based phylogenetic framework for

505 analyzing these data, incomplete taxon sampling, and a paucity of molecular research in

506 intervening years have left important questions unanswered (e.g., Table 1). We

507 addressed this using the most taxonomically complete sequence dataset available for

508 Urocitellus, evaluating mtDNA and nuclear loci independently, and utilizing 3

509 methodologically distinct species tree methods that should also differ in their sensitivity

510 to mtDNA inclusion as well as to isolated introgression events.

511

512 A crucial first step in understanding Urocitellus diversification lies in fully resolving the

513 phylogenetic status of big-eared and small-eared groups. Small-eared Urocitellus are

514 small-bodied, adapted to life in arid environments and geographically narrowly restricted

515 to the Great Basin and surrounding regions of western North America (Fig. 2). In

516 contrast, big-eared species are up to an order of magnitude larger in size (in U. parryii),

517 more mesic-adapted, occupy larger geographic ranges, and have a much wider 
518 latitudinal distribution that also spans multiple continents (Fig. 1). Some big-eared

519 species also display extreme physiological adaptations for hibernation (Barnes 1989,

520 Boyer and Barnes 1999). Reciprocal monophyly of these groups would therefore

521 presumably represent an important adaptive dichotomy within the genus.

522

523 All species tree reconstruction methods ( ${ }^{*} \mathrm{BEAST}, \mathrm{STAR}, \mathrm{MP}-\mathrm{EST}$ ) indicate this

524 dichotomy exists, but support for monophyly of the groups varies from moderate to very

525 high depending on the dataset and species tree reconstruction method. We also

526 recovered moderate to high support (0.79-0.99 nodal support; Fig. 6) for monophyly of a

527 'townsendii complex' within the small-eared group. These small-eared taxa are similar in

528 morphology and protein electrophoretic characters (Nadler et al. 1974), but divergent in

529 karyotype (2N=36-46; Nadler 1966, Rickart 1985). Thus, our results suggest that these

530 latter taxa are sister species that have undergone instances of significant chromosomal

531 evolution in spite of their morphological conservatism.

532

533 We submit that our inability to accept the phylogenetic hypotheses above is due to

534 pervasive ILS owing to rapid diversification of Urocitellus, which itself is reflective of the

535 larger radiation of marmotine ground squirrels. That scenario is supported by the poor

536 resolution within, as well as topological disparity among, gene trees (Figs. 5 and A.1),

537 each of which point to ILS concentrated deep in Urocitellus phylogeny. While this

538 resulted in negative tests for many hypotheses, we note that such results may not be

539 consistent with formal rejection of phylogenetic hypotheses. Instead, failure to obtain

540 robust clade-level support may be due to low statistical power, directly resulting from

541 insufficient information in nuclear loci. Nevertheless, such inconclusive results were

542 surprising given the amount of data available (5270bp), variability present in locus-

543 specific mutational profiles (Table A.2), and evidence from previous studies 
544 demonstrating the power of the coalescent function in *BEAST (Lanier et al. 2014) and

545 the performance of STAR and MP-EST (Degiorgio and Degnan 2014) in spite of

546 moderate ILS. In the future, higher statistical power may be found with genome-scale

547 sampling of Urocitellus.

548

5494.2 Sources of mtDNA Non-Monophyly in Urocitellus

550

551 ILS, hybridization and incorrect species delimitation are 3 common explanations for non-

552 monophyly in gene trees of vertebrate species (McKay and Zink 2010). While

553 hybridization and ILS result in true non-monophyly of gene copies, incorrect species

554 delimitation can lead to discordance between gene trees and recognized taxonomic

555 boundaries (McKay and Zink 2010). As we discuss, ILS is apparent at the interspecific

556 level in Urocitellus, particularly in nuclear loci. Yet, despite this, species delimitation

557 remains possible in many cases (Table 1 and Fig. A.1). Our taxonomically

558 comprehensive multilocus dataset therefore allowed robust evaluation of current

559 systematic and taxonomic arrangements at and below the species level; this includes

560 the latter 3 phylogenetic hypotheses outlined above (i.e., monophyly of $U$. parryii, $U$.

561 elegans and U. mollis; Table 1).

562

563 Phylogenetic inferences, as well as posterior predictive simulations, support

564 hybridization leading to introgression as the source of mtDNA non-monophyly in $U$.

565 parryii and $U$. elegans. We hypothesize that mtDNA gene flow occurred twice: first, from

566 the Arctic clade of U. parryii (U. p. kennicottii or U. p. parryii) to the subspecies U. e.

567 elegans, and second, from U. e. elegans to U. richardsonii (Fig. 8). Our study

568 demonstrates the importance of a posterior predictive approach in particular when

569 attempting to distinguish hybridization from ILS as explaining mitonuclear discordance. 
570 While we were unable to reject a role for ILS at the $p=0.05$ level, we note that the

571 statistical power of the JML approach is sensitive to misspecification of substitution

572 model parameters, length of the locus under investigation, and the time elapsed

573 between events of speciation and hybridization (Joly et al. 2009). Thus, close

574 relationship of members of the PRE clade as well as the small length of CYTB (1140bp)

575 could explain why we attained only marginal statistical significance in rejecting ILS in this

576 instance. Additional mtDNA data (to increase sequence length) as well as nuclear data

577 (to further increase precision of species tree estimates) would be useful to further test

578 our proposed hybridization hypothesis.

579

580 Conversely, there is no support for either ILS or hybridization as a driver of mtDNA non-

581 monophyly in U. mollis. ILS is unlikely due to the expected faster sorting of mtDNA

582 relative to nuclear loci, coupled with the fact that nuclear loci often delimit other

583 Urocitellus species (but never U. mollis; Table 1). Hybridization (with U. canus) was also

584 unsupported by JML, despite the performance of the method for closely related species

585 in the PRE clade (we note that U. c. canus was not included in JML runs, however). We

586 therefore hypothesize that current taxonomy inaccurately reflects species boundaries in

587 this taxon. Indeed, multiple species were originally described from within U. mollis (e.g.,

588 Merriam 1913), and electrophoretic differences were reported among subspecies

589 (Nadler et al. 1974). Expanded sampling is therefore warranted for accurate species

590 delimitation in U. mollis. Future work should focus on range-wide sampling, especially

591 along the Snake River, Idaho, where ranges of subspecies U. m. artemesiae and U. m.

592 idahoensis abut that of U. m. mollis (Fig. 2).

593

594 Finally, it is interesting that posterior predictive checking rejected a role for ILS in

595 explaining patterns of mtDNA genetic distance between $U$. beldingi and $U$. mollis (the $U$. 
596 beldingi - $U$. canus comparison was also significant at the $p=0.1$ level; Table 2$)$. There is

597 no evidence for hybridization among these taxa in mtDNA. Instead of hybridization, our

598 results may result from the large discrepancies in $U$. beldingi placement within the big-

599 eared clade existing between mtDNA and species trees (Figs. 3 and 6). Specifically,

600 uncertainty in *BEAST species tree posterior distributions could lead to an inflation of

601 simulated mtDNA distances between $U$. beldingi and small-eared taxa such as $U$. mollis

602 relative to that observed in empirical data. Such a scenario could result in increased

603 susceptibility of the posterior predictive approach to Type I error in cases where species

604 trees are poorly resolved, but mtDNA (or other single locus) trees display high and

605 conflicting support. Application of the method to similar situations in additional clades is

606 therefore warranted.

607

$608 \quad 4.3$ The Biogeography of Diversification in Urocitellus

609

610 Differences in the distribution and habitat preferences of small-eared and big-eared

611 Urocitellus have long been recognized (Howell 1938, Davis 1939, Durrant and Hansen

612 1954), but new insights as well as questions emerge when viewed in light of our results.

613 A clear feature of Urocitellus evolution is colonization of high latitudes and altitudes by

614 members of the big-eared group (Fig. 1). Four of these species inhabit latitudes higher

615 than $50^{\circ} \mathrm{N}$ : U. columbianus (northern Rocky Mountains), U. richardsonii (northern Great

616 Plains), U. parryii (North American high arctic and Siberia), and U. undulatus (central

617 Asia and Siberia). Our results suggest multiple high latitude colonizations occurred in the

618 history of the genus, which is notable given the demands of arctic and subarctic

619 existence on homeothermic animals. However, the number and timing of arctic

620 colonizations in particular remains uncertain. The exclusively Palearctic $U$. undulatus

621 must have colonized Asia via Beringia just as U. parryii has done more recently 
622 (Galbreath et al. 2011); if $U$. undulatus shares a most recent common ancestor with the

623 PRE clade (as suggested by mtDNA, *BEAST and STAR analyses), then colonization of

624 arctic habitats must have occurred only once. However, additional data are needed to

625 rule out an alternative scenario of 2 distinct arctic colonization events.

626

627 The concept of high-latitude diversification and adaptation is perhaps best embodied by

628 the Arctic ground squirrel (U. parryii), which is the northernmost species of squirrel in the

629 world. Intraspecific diversification of U. parryii within Beringia has been strongly shaped

630 by Quaternary climate change (Eddingsaas et al. 2004, Galbreath et al. 2011, Nadler

631 and Hoffmann 1977), and our data shed additional light on that history. First, we show

632 that the Arctic clade of U. parryii is widespread across the North American high arctic

633 (Fig. 8), such that it likely expanded from a Nearctic glacial refugium following the Last

634 Glacial Maximum. We also demonstrate the occurrence of 2 separate mtDNA clades in

635 core Beringia during the late Pleistocene, each of which currently persists in North

636 American and Asian refugia. Based on that result, these clades (Beringia and Southwest

637 [Alaska] clades sensu Cook et al. 2010, Eddingsaas et al. 2004, Galbreath et al. 2011)

638 are best considered the "Northern Beringia" and "Southern Beringia" clades (Fig. 8; for

639 the purposes of this study, we include the Southeast clade of previous authors in the

640 "Northern Beringia" clade). The alliance of U. p. stejnegeri with the southwestern Alaska

641 mtDNA clade (U. p. ablusus, U. p. kodiacensis, U. p. nebulicola) to comprise the

642 Southern Beringia clade reveals a previously unrecognized level of mtDNA diversity in

643 the Palearctic, and we note that this fails to support recent taxonomic treatments

644 subsuming all Palearctic U. parryii into a single subspecies (U. p. leucostictus; Kryštufek

645 and Vohralík 2013).

646 The phylogeographic patterns discussed above are intriguing because late Pleistocene 
647 Beringia is often reconstructed as an open steppe environment. However, Guthrie

648 (2001) proposed a Beringian "mesic buckle" as an ecological barrier for some

649 Pleistocene fauna, comprised of mesic tundra or forest and stretching north-south in the

650 region of the modern-day Bering Strait. If inhospitable enough, this or other features may

651 have fostered the isolation of U. parryii mtDNA clades in core Beringia, even if they were

652 somewhat porous in space or time. In contrast, nuclear data have been interpreted as

653 telling a story of high migration between the Northern Beringia and Southern Beringia

654 clades (Galbreath et al. 2011). Those authors hypothesized that the significant

655 structuring of mtDNA relative to nuclear loci could be driven by female philopatry and

656 highly male-biased dispersal (Byrom and Krebs 1999, Karels and Boonstra 2000), which

657 our data further support. In the future, it will be important to investigate whether a

658 narrative of elevated mtDNA diversification, driven by demographic biases and

659 superimposed on contrasting nuclear backgrounds, characterizes additional Urocitellus

660 across the Holarctic.

661 The biogeographic patterns we outline for the big-eared group stand in contrast to those

662 of small-eared Urocitellus, which are geographically limited to areas in and surrounding

663 the Great Basin. Range sizes of small-eared taxa are also relatively small (except U. $\mathrm{m}$.

664 mollis). However, to date, the processes that have promoted diversification of low-

665 elevation taxa (such as Urocitellus) in this region remain poorly understood (Riddle et al.

666 2014). Figure 2 highlights the geographic apportionment of diversity in small-eared

667 Urocitellus, which appears demarcated in several instances by major river drainages.

668 We therefore consider it possible that the evolutionary narrative of small-eared taxa is

669 one of long-term endemism and in situ allopatric diversification within the Great Basin

670 shrub-steppe ecosystem, potentially induced by shifts in the presence and location of 
671 glacial lakes and ancient/modern river systems. Testing this hypothesis will be possible

672 with ongoing geographic sampling and taxonomic reconsideration of the group.

673

674 Finally, full resolution of Urocitellus phylogeny and completion of species-level

675 phylogeographies will be paramount for effective management of imperiled taxa. This is

676 particularly true for small-eared species, whose disproportionate representation on

677 conservation lists is at least partly related to their restricted geographic distribution.

678 Under the U.S. Endangered Species Act, 1 subspecies (U. brunneus brunneus) is

679 currently listed as Threatened, 1 species (U. washingtoni) is listed as Candidate, and

680 another species is Of Concern (U. townsendii). Anecdotal evidence for population-level

681 declines also exists in U. canus (Yensen and Sherman 2003). Perhaps the most

682 pressing result of our analysis is recovery of the Idaho ground squirrel (U. brunneus) as

683 basal to the remainder of small-eared species, a relationship not supported by mtDNA or

684 even most nuclear genes individually (Figs. 3 and A.1; Harrison et al. 2003). U.

685 brunneus has the most restricted geographic distribution of any Urocitellus (5 counties in

686 western Idaho; Fig. 2), and our data suggest the possibility that it is an ancient and

687 divergent lineage. This places renewed importance on continued monitoring of natural

688 and anthropogenic threats to this taxon.

689

690 4.4 What Drives Hybridization in Marmotini?

691

692 Rapidly radiating clades are ideal systems for examining many evolutionary phenomena, 693 including the interaction of hybridization and diversification. Maddison (1997) and others

694 have suggested that phylogeny is not only a depiction of historical splitting events, but

695 also a history of changing probabilities of interbreeding. Mallet (2005) calculated that

696 roughly $10 \%$ of animal species hybridize, and it is now apparent that gene flow can 
697 proceed at various points along the speciation continuum without interrupting or

698 reversing speciation itself (e.g., Evans et al. 2001, Koepfli et al. 2015, Melo-Ferreira et

699 al. 2012, Sullivan et al. 2014). Yet some clades appear more prone to hybridization than

700 others, and conclusive examples of hybridization now exist in at least 6 of 11 recognized

701 marmotine genera containing >1 species (Hafner and Yates 1983, Kerhoulas et al. 2015,

702 Nadler et al. 1971, Spiridinova et al. 2006, Sullivan et al. 2014, Thompson et al. 2015).

703 But what are the factors facilitating such widespread gene flow?

704

705 We identify 3 potential drivers of hybridization in Urocitellus that are not mutually

706 exclusive and may also extend to other ground squirrel genera. First, squirrels in general

707 and ground squirrels in particular are morphologically conserved (Casanovas-Vilar and

708 van Dam 2013, Emry and Thorington 1984, Zeldtich et al. 2015). Morphological

709 diversification in Urocitellus has been reconstructed as among the lowest of all

710 marmotine clades (Zelditch et al. 2015), and a significant amount of standing

711 morphological variation in this genus may simply be due to allometry (Pearson 1981,

712 Robinson and Hoffmann 1975, BSM unpublished data). A similar pattern of

713 conservatism in those morphological traits directly involved in prezygotic incompatibility

714 could facilitate widespread hybridization.

715 Second, conservatism in ecologically relevant traits, such as phenology and habitat

716 preference, could also drive hybridization. There is overlap in both of these traits within

717 each of the small-eared and big-eared groups of Urocitellus. For example, most big-

718 eared species occur in parapatry across mesic and semi-arid grasslands of western

719 North America (Fig. 1). They are known to partition habitat in zones of sympatry, but not

720 in allopatry, suggesting a lack of ecological differentiation (Durrant and Hansen 1954).

721 Additionally, habitat partitioning in sympatry can be incomplete, resulting in existence of 
722 species pairs in syntopy (Davis 1939, Durrant and Hansen 1954, McLean personal

723 observation). Such a lack of differentiation could facilitate hybridization if other major

724 isolating mechanisms are absent, similar to what has been documented in non-sister

725 species of Tamias chipmunks (Good et al. 2008, Reid et al. 2010, Sullivan et al. 2014).

726 Third, Quaternary climate change has repeatedly reorganized faunal and floral

727 communities, creating significant opportunities for secondary contact and gene flow. This

728 is particularly true at high northern latitudes (Hewitt 2000, Lessa et al. 2003), which are

729 themselves emerging as prime venues for investigating the interplay of rodent

730 diversification and hybridization (Chavez et al. 2014, Kerhoulas et al. 2015, Runck et al.

731 2009). The power of past climate change to create unique and unpredictable

732 opportunities for gene flow is evidenced in the PRE clade; not only do all 3 taxa now

733 occur in allopatry, but the directionality of gene flow we propose is unparsimonious with

734 reference to current distributions. First, hybridization occurred between $U$. parryii and $U$.

735 e. elegans despite the fact that the range of $U$. richardsonii currently lies between them.

736 Second, according to our proposed scenario, it was the Arctic clade of U. parryii (not the

737 geographically proximate U. p. plesius) that came into contact with U. e. elegans. Third,

738 secondary introgression occurred between U. e. elegans and U. richardsonii despite the

739 fact that $U$. richardsonii is currently sympatric only with $U$. e. aureus, with which it is

740 documented to hybridize (Nadler et al. 1971) but has not shared mtDNA. Thus, while the

741 lack of morphological or ecological isolating mechanisms sets a biological "stage" for

742 hybridization, climatic and geographic contingencies can act as potent drivers of this

743 process. A rigorous historical perspective will be crucial to future assessments of

744 hybridization dynamics in other northern taxa.

745

746 4.4 The Possibility of Adaptive Gene Flow in Urocitellus 
748 The ultimate role of hybridization in animal diversification remains incompletely

749 understood (but see Hedrick 2013). Wiens et al. (2006) suggested that, in rapidly

750 diversifying clades, hybridization might be a consequence of radiation, with speciation

751 outpacing the evolution of reproductive incompatibilities. Seehausen (2004) suggested

752 that hybridization might also drive radiations through transfer of adaptive variation. Both

753 models accommodate hybridization as adaptive, but that of Seehausen (2004) posits a

754 causal role for adaptive introgression in radiations.

755

756 Many authors have ascribed instances of mtDNA introgression to adaptive advantage of

757 mtDNA haplotypes (Toews and Brelsford 2012), but evidence for this is slim, largely

758 because it requires linking mtDNA functionality to individual fitness consequences (Storz

759 and Wheat 2010). However, evidence is mounting that mtDNA variation does underlie

760 important respiration-related adaptations (Shen et al. 2010, Scott et al. 2015, Toews et

761 al. 2013, Wilson et al. 2013), and that differential fitness consequences can also result

762 from interactions of mtDNA superimposed on different nuclear backgrounds (Ellison and

763 Burton 2006, Hill et al. 2015, Levin et al. 2014).

764

765 Was hybridization adaptive in Urocitellus? Or was this a nonadaptive result of secondary

766 contact between reproductively compatible species, driven by Quaternary climate cycling

767 and/or demographic change? All Urocitellus are obligate hibernators (Thorington et al.

768 2012), but $U$. parryii is considered an extreme hibernator, capable of enduring body

769 temperatures below $0^{\circ} \mathrm{C}$ for several weeks (Barnes 1989, Buck and Barnes 1999).

770 Mitochondria are main sites for cellular energy production and play crucial roles during

771 hibernation and intermittent arousals in mammals, such as maintaining body

772 temperatures above subzero arctic soil temperatures and functioning in non-shivering 
773 thermogenesis (Staples 2014, Staples and Brown 2008). The potential for mtDNA

774 introgression in Urocitellus to be driven by adaptive advantage of U. parryii mtDNA

775 should therefore continue to be explored.

776

777 5. Conclusion

778

779 We investigated phylogeny of Urocitellus, a geographically widespread clade of ground

780 squirrels whose evolutionary history has heretofore been incompletely understood. In

781 doing so, we found the genomic history of this genus to be complex, characterized not

782 only by pervasive ILS but also ancient hybridization among high-latitude taxa. These

783 results represent important new insights into dynamics of Urocitellus diversification, but

784 additional data are needed to fully parse these multiple drivers of gene tree discordance

785 and thus resolve several recalcitrant phylogenetic and systematic questions. Application

786 of genome-scale data to those issues, as well as to the issue of whether there is

787 adaptive significance to the widespread hybridization that has been documented across

788 Marmotini, is an important research direction to pursue.

789

790

791 Acknowledgments:

792

793 Funding for this research was provided by the National Science Foundation (NSF

794 1258010), UNM Department of Biology (Joseph Gaudin Scholarship), UNM Graduate

795 and Professional Student Association, and UNM Biology Graduate Student Association.

796 The following curators provided access to important museum specimens: Kristofer

797 Helgen (NMNH); Jim Patton, Eileen Lacey, Michael Nachman (MVZ); Eric Rickart

798 (UMNH); Sharlene Santana (UWBM); Larry Heaney, Bruce Patterson (FMNH); Duke 
799 Rogers (MLBM); Burton Lim (ROM); John Demboski (DMNS). We acknowledge

800 important insights of Kurt Galbreath, Kayce Bell, and additional members of the Cook

801 Lab at UNM that significantly improved the quality of this manuscript.

802

803

804 References

805 Adkins, R.M., Gelke, E.L., Rowe, D., Honeycutt, R.L., 2001. Molecular phylogeny and 806 divergence time estimates for major rodent groups: evidence from multiple 807 genes. Mol. Biol. Evol. 18, 777-791. doi:10.1093/oxfordjournals.molbev.a003860

808 Alfaro, M.E., Holder, M.T., 2006. The posterior and the prior in Bayesian phylogenetics.

$809 \quad$ Annu. Rev. Ecol. Evol. Syst. 37, 19-42.

$810 \quad$ doi:10.1146/annurev.ecolsys.37.091305.110021

811 Alfaro, M.E., Zoller, S., Lutzoni, F., 2003. Bayes or bootstrap? A simulation study

812 comparing the performance of Bayesian Markov Chain Monte Carlo sampling

813 and bootstrapping in assessing phylogenetic confidence. Mol. Biol. Evol. 20,

$814 \quad$ 255-266. doi:10.1093/molbev/msg028

815 Arnold, M.L. 2006. Evolution Through Genetic Exchange. Oxford University Press, New $816 \quad$ York.

817 Barnes, B.M., 1989. Freeze avoidance in a mammal: body temperatures below 0

818 degrees C in an Arctic hibernator. Science 244, 1593-1595.

819 doi:10.1126/science.2740905 
820 Boyer, B.B., Barnes, B.M., 1999. Molecular and metabolic aspects of mammalian

821 hibernation. Bioscience 49, 713-724. doi:10.2307/1313595

822 Byrom, A.E., Krebs, C.J., 1999. Natal dispersal of juvenile arctic ground squirrels in the 823 boreal forest. Can. J. Zool. 77, 1048-1059. doi:10.1139/cjz-77-7-1048

824 Casanovas-Vilar, I., van Dam, J., 2013. Conservatism and adaptability during squirrel 825 radiation: what is mandible shape telling us? PLoS One 8, e61298.

826 doi:10.1371/journal.pone.0061298

827 Chavez, A.S., Maher, S.P., Arbogast, B.S., Kenagy, G.J., 2014. Diversification and gene 828 flow in nascent lineages of island and mainland North American tree squirrels 829 (Tamiasciurus). Evolution 68, 1094-1109. doi:10.1111/evo.12336

830 Cole, F.R., Wilson, D.E., 2009. Urocitellus canus. Mamm. Species 834, 1-8. $831 \quad$ doi:http://dx.doi.org/10.1644/834.1.

832 Cook, J.A., Eddingsaas, A.A., Loxterman, J.L., Ebbert, S., MacDonald, S.O., 2010. 833 Insular arctic ground squirrels (Spermophilus parryii) of the North Pacific:

834 indigenous or exotic? J. Mammal. 91, 1401-1412. doi:10.1644/09-MAMM-A$835 \quad 386.1$. Key

836 Cui, R., Schumer, M., Kruesi, K., Walter, R., Andolfatto, P., Rosenthal, G.G., 2013. 837 Phylogenomics reveals extensive reticulate evolution in Xiphophorus fishes. $838 \quad$ Evolution 67, 2166-2179. doi:10.1111/evo.12099

839 Davis, W.B., 1939. The Recent Mammals of Idaho. The Caxton Printers, Ltd., Caldwell, $840 \quad$ Idaho. 
841 DeGiorgio, M., Degnan, J.H., 2014. Robustness to divergence time underestimation 842 when inferring species trees from estimated gene trees. Syst. Biol. 63, 66-82. 843 doi:10.1093/sysbio/syt059

844 Degnan, J.H., Rosenberg, N.A., 2006. Discordance of species trees with their most likely 845 gene trees. PLoS Genet. 2, e68. doi:10.1371/journal.pgen.0020068

846 Drummond, A.J., Suchard, M.A., Xie, D., Rambaut, A., 2012. Bayesian Phylogenetics $847 \quad$ with BEAUti and the BEAST 1.7. Mol. Biol. Evol. 29, 1969-1973.

$848 \quad$ doi:10.1093/molbev/mss075

849 Durrant, S.D., Hansen, R.M., 1954. Distribution patterns and phylogeny of some $850 \quad$ western ground squirrels. Syst. Zool. 3, 82-85. doi:10.2307/2411841

851

852 Eddingsaas, A.A., Jacobsen, B.K., Lessa, E.P., Cook, J.A., 2004. Evolutionary history of 853 the arctic ground squirrel (Spermophilus parryii) in Nearctic Beringia. J. Mammal. 854 85, 601-610. doi: http://dx.doi.org/10.1644/BRB-204

855 Edgar, R.C., 2004. MUSCLE: Multiple sequence alignment with high accuracy and high 856 throughput. Nucleic Acids Res. 32, 1792-1797. doi:10.1093/nar/gkh340

857 Ellison, C.K., Burton, R.S., 2008. Genotype-dependent variation of mitochondrial 858 transcriptional profiles in interpopulation hybrids. Proc. Natl. Acad. Sci. U. S. A.

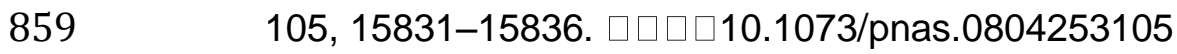

860 Emry, R.J., Thorington, R.W., 1982. Descriptive and comparative osteology of the oldest 861 fossil squirrel, Protosciurus (Rodentia: Sciuridae). Smithson. Contrib. to

$862 \quad$ Paleobiol. 1-35. doi:10.5479/si.00810266.47.1 
863 Evans, B.J., Supriatna, J., Melnick, D.J., 2001. Hybridization and populations genetics of 864 two macaque species in Sulawesi, Indonesia. Evolution 55, 1886-1702.

865 doi:10.1554/0014-3820(2001)055

866 Felsenstein, J., Churchill, G.A., 1996. A Hidden Markov Model approach to variation 867 among sites in rate of evolution. Mol. Biol. Evol. 13, 93-104.

868 Galbreath, K.E., Cook, J.A., Eddingsaas, A.A., Dechaine, E.G., 2011. Diversity and 869 demography in Beringia: multilocus tests of paleodistribution models reveal the $870 \quad$ complex history of arctic ground squirrels. Evolution 65, 1879-96.

$871 \quad$ doi:10.1111/j.1558-5646.2011.01287.x

872 Garroway, C.J., Bowman, J., Cascaden, T.J., Holloway, G.L., Mahan, C.G., Malcolm, 873 J.R., Steele, M.A., Turner, G., Wilson, P.J., 2010. Climate change induced 874 hybridization in flying squirrels. Glob. Chang. Biol. 16, 113-121.

$875 \quad$ doi:10.1111/j.1365-2486.2009.01948.x

876 Good, J.M., Hird, S., Reid, N., Demboski, J.R., Steppan, S.J., Martin-Nims, T.R., 877 Sullivan, J., 2008. Ancient hybridization and mitochondrial capture between two 878 species of chipmunks. Mol. Ecol. 17, 1313-1327. doi:10.1111/j.1365$879 \quad 294 X .2007 .03640 . x$

880 Good, J.M., Vanderpool, D., Keeble, S., Bi, K., 2015. Negligible nuclear introgression 881 despite complete mitochondrial capture between two species of chipmunks.

$882 \quad$ Evolution 69, 1961-1972. doi:10.1111/evo.12712 
883 Guthrie, R.D., 2001. Origin and causes of the mammoth steppe: a story of cloud cover, 884 woolly mammal tooth pits, buckles, and inside-out Beringia. Quat. Sci. Rev. 20, 885 549-574. doi:http://dx.doi.org/10.1016/S0277-3791(00)00099-8

886 Hafner, D.J., 1984. Evolutionary Relationships of the Nearctic Sciuridae, in: Murie, J.O., 887 Michener, G.R. (Eds.), The Biology of Ground-Dwelling Sciurids. University of $888 \quad$ Nebraska Press, Lincoln, pp. 3-23.

889 Hafner, D.J., Yates, T.L., 1983. Systematic status of the Mojave ground squirrel, 890 Spermophilus mohavensis (subgenus Xerospermophilus). J. Mammal. 64, 397891 404. doi:http://dx.doi.org/10.2307/1380352

892

893 Harrison, R.G., Bogdanowicz, S.M., Hoffmann, R.S., Yensen, E., Sherman, P.W., 2003.

894 Phylogeny and evolutionary history of the ground squirrels (Rodentia:

895 Marmotinae). J. Mamm. Evol. 10, 249-276.

896 doi:10.1023/b:jomm.0000015105.96065.f0

897 Hedrick, P.W., 2013. Adaptive introgression in animals: examples and comparison to 898 new mutation and standing variation as sources of adaptive variation. Mol. Ecol. $89922,4606-4618$. doi:10.1111/mec.12415

900 Helgen, K.M., Cole, F.R., Helgen, L.E., Wilson, D.E., 2009. Generic revision in the 901 Holarctic ground squirrel genus Spermophilus. J. Mammal. 90, 270-305.

902 doi:http://dx.doi.org/10.1644/07-MAMM-A-309.1

903 Hewitt, G., 2000. The genetic legacy of the Quaternary ice ages. Nature 405, 907-913.

904 doi: $10.1038 / 35016000$ 
905 Hill, G.E., 2015. Mitonuclear ecology. Mol. Biol. Evol. 32, 1917-1927.

906 doi:10.1093/molbev/msv104

907 Hillis, D.M., Heath, T.A., St. John, K., 2005. Analysis and visualization of tree space.

$908 \quad$ Syst. Biol. 54, 471-482. doi:10.1080/10635150590946961

909 Holder, M.T., Anderson, J.A., Holloway, A.K., 2000. Difficulties in detecting hybridization.

$910 \quad$ Syst. Biol. 50, 978-982. doi:10.1080/106351501753462911

911 Howell, A.H., 1938. Revision of the North American Ground Squirrels, with a

912 Classification of the North American Sciuridae. North Am. Fauna 56.

913 doi:http://dx.doi.org/10.3996/nafa.56.0001

914 Huchon, D., Catzeflis, F.M., Douzery, E.J.P., 1999. Molecular evolution of the nuclear

915 von Willebrand factor gene in mammals and the phylogeny of rodents. Mol. Biol.

$916 \quad$ Evol. 16, 577-589.

917 Huelsenbeck, J.P., Larget, B., Alfaro, M.E., 2004. Bayesian phylogenetic model

918 selection using reversible jump markov chain monte carlo. Mol. Biol. Evol. 21,

919 1123-1133. doi:10.1093/molbev/msh123

920 Jockusch, E.L., Martinez-Solano, I., Timpe, E.K., 2015. The effects of inference method,

921 population sampling, and gene sampling on species tree inferences: an empirical

922 study in slender salamanders (Plethodontidae: Batrachoseps). Syst. Biol. 64, 66-

923 83. doi:10.1093/sysbio/syu078

924 Joly, S., 2012. JML: Testing hybridization from species trees. Mol. Ecol. Resour. 12,

$925 \quad$ 179-184. doi:10.1111/j.1755-0998.2011.03065.x 
926 Joly, S., McLenachan, P.A., Lockhart, P.J., 2009. A statistical approach for

927 distinguishing hybridization and incomplete lineage sorting. Am. Nat. 174, E54-

$928 \quad$ E70. doi:10.1086/600082

929 Joyce, D.A., Lunt, D.H., Genner, M.J., Turner, G.F., Bills, R., Seehausen, O., 2011.

930 Repeated colonization and hybridization in Lake Malawi cichlids. Curr. Biol. 21,

$931 \quad$ R108-R109. doi:10.1016/j.cub.2010.11.029

932 Karels, T.J., Boonstra, R., 2000. Concurrent density dependence and independence in

933 populations of arctic ground squirrels. Nature 408, 460-463.

934 doi: $10.1038 / 35044064$

935 Kerhoulas, N.J., Gunderson, A.M., Olson, L.E., 2015. Complex history of isolation and

936 gene flow in hoary, Olympic, and endangered Vancouver Island marmots. J.

937 Mammal. 96, 810-826. doi:10.1093/jmammal/gyv089

938 Koepfli, K.-P., Pollinger, J., Godinho, R., Robinson, J., Lea, A., Hendricks, S.,

939 Schweizer, R.M., Thalmann, O., Silva, P., Fan, Z., Yurchenko, A.A., Dobrynin, P.,

940 Makunin, A., Cahill, J.A., Shapiro, B., Álvares, F., Brito, J.C., Geffen, E., Leonard,

941 J.A., Helgen, K.M., Johnson, W.E., O’Brien, S.J., Van Valkenburgh, B., Wayne,

942 R.K., 2015. Genome-wide evidence reveals that African and Eurasian golden

943 jackals are distinct species. Curr. Biol. 25, 2158-2165.

944 doi:10.1016/j.cub.2015.06.060

945 Krystufek, B., Vohralik, V., 2013. Taxonomic revision of the Palaearctic rodents

946 (Rodentia). Part 2. Sciuridae: Urocitellus, Marmota and Sciurotamias. Lynx 44,

$947 \quad 27-138$. 
948 Lanier, H.C., Huang, H., Knowles, L.L., 2014. How low can you go? The effects of

949 mutation rate on the accuracy of species-tree estimation. Mol. Phylogenet. Evol.

$950 \quad 70,112-119$. doi:10.1016/j.ympev.2013.09.006

951 Leache, A.D., Harris, R.B., Rannala, B., Yang, Z., 2014. The influence of gene flow on

952 species tree estimation: a simulation study. Syst. Biol. 63, 17-30.

953 doi:10.1093/sysbio/syt049

954 Lessa, E.P., Cook, J.A., Patton, J.L., 2003. Genetic footprints of demographic expansion

955 in North America, but not Amazonia, during the Late Quaternary. Proc. Natl.

956 Acad. Sci. U. S. A. 100, 10331-10334. doi:10.1073/pnas.1730921100

957 Levin, L., Blumberg, A., Barshad, G., Mishmar, D., 2014. Mito-nuclear co-evolution: the

958 positive and negative sides of functional ancient mutations. Front. Genet. 5, 448.

959 doi:10.3389/fgene.2014.00448

960 Liu, L., Yu, L., Edwards, S. V, 2010. A maximum pseudo-likelihood approach for

961 estimating species trees under the coalescent model. BMC Evol. Biol. 10, 302.

962 doi:10.1186/1471-2148-10-302

963 Liu, L., Yu, L., Pearl, D.K., Edwards, S. V, 2009. Estimating species phylogenies using

964 coalescence times among sequences. Syst. Biol. 58, 468-77.

965 doi:10.1093/sysbio/syp031

966 Maddison, W.P., 1997. Gene trees in species trees. Syst. Biol. 46, 523-536.

967 doi:10.1093/sysbio/46.3.523

968 Maddison, W.P., Maddison, D.R., 2015. Mesquite: a modular system for evolutionary $969 \quad$ analysis. 
970 Mallet, J., 2005. Hybridization as an invasion of the genome. Trends Ecol. Evol. 20,

971 229-237. doi:10.1016/j.tree.2005.02.010

972 Martin, S.H., Dasmahapatra, K.K., Nadeau, N.J., Salazar, C., Walters, J.R., Simpson, F.,

973 Blaxter, M., Manica, A., Mallet, J., Jiggins, C.D., 2013. Genome-wide evidence

$974 \quad$ for speciation with gene flow in Heliconius butterflies. Genome Res. 23, 1817-

$975 \quad$ 1828. doi:10.1101/gr.159426.113.

976 McKay, B.D., Zink, R.M., 2010. The causes of mitochondrial DNA gene tree paraphyly in 977 birds. Mol. Phylogenet. Evol. 54, 647-650. doi:10.1016/j.ympev.2009.08.024

978 Melo-Ferreira, J., Boursot, P., Carneiro, M., Esteves, P.J., Farelo, L., Alves, P.C., 2012.

979 Recurrent introgression of mitochondrial DNA among hares (Lepus spp.)

980 revealed by species-tree inference and coalescent simulations. Syst. Biol. 61,

$981 \quad 367-381$. doi:10.1093/sysbio/syr114

982 Merriam, C.H., 1913. Six new ground squirrels of the Citellus mollis group from Idaho, 983 Oregon, and Nevada. Proc. Biol. Soc. Washingt. 26, 135-138.

984 Murie, J.O., Michener, G.R. (Eds.), 1984. The Biology of Ground-Dwelling Squirrels:

985 Annual Cycles, Behavioral Ecology and Sociality. University of Nebraska Press, $986 \quad$ Lincoln.

987 Nadler, C.F., 1966. Chromosomes and systematics of American ground squirrels of the 988 subgenus Spermophilus. J. Mammal. 47, 579-596.

989 doi:http://dx.doi.org/10.2307/1377889

990 
991 Nadler, C.F., Hoffmann, R.S., 1977. Patterns of evolution and migration in the arctic

992 ground squirrel, Spermophilus parryii (Richardson). Can. J. Zool. 55, 748-758.

993 doi:10.1139/z77-097

994

995 Nadler, C.F., Hoffmann, R.S., Greer, K.R., 1971. Chromosomal divergence during

996 evolution of ground squirrel populations (Rodentia: Spermophilus). Syst. Zool.

997 20, 298-305. doi:10.2307/2412342

998 Nadler, C.F., Hoffmann, R.S., Vorontsov, N.N., Koeppl, J.W., Deutsch, L., Sukernik, R.I., 999 1982. Evolution in ground squirrels: II. Biochemical comparisons in Holarctic 1000 populations of Spermophilus. Zeitschrift Fur Saugetierkd. 47, 198-215.

1001 Nadler, C.F., Lyapunova, E.A., Hoffmann, R.S., Vorontsov, N.N., Shaitarova, L.L., 1002 Borisov, Y.M., 1984. Chromosomal evolution in Holarctic ground squirrels II. 1003 Giemsa-band homologies of chromosomes and the tempo of evolution. 1004 Zeitschrift Fur Saugetierkd. 49, 78-90.

1005 Nadler, C.F., Sukernik, R.I., Hoffmann, R.S., Vorontsov, N.N., Nadler Jr., C.F., 1006 Fomichova, I.I., 1974. Evolution in ground squirrels I. Transferrins in Holarctic 1007 populations of Spermophilus. Comp. Biochem. Physiol. A 47, 663-681.

1008 Paradis, E., Bolker, B., Claude, J., Cuong, H.S., Desper, R., Durand, B., Dutheil, J., 1009 Gascuel, O., Heibl, C., Lawson, D., Lefort, V., Legendre, P., Lemon, J., Noel, Y., 1010 Nylander, J., Opgen-Rhein, R., Popescu, A.-A., Schliep, K., Strimmer, K., de 1011 Vienne, D., 2013. ape: Analyses of Phylogenetics and Evolution. 
1012 Pfeifer, B., Wittelsbuerger, U., Ramos-Onsins, S.E., Lercher, M.J. 2014. PopGenome:

1013 an efficient Swiss army knife for population genomic analyses in R. Mol. Biol.

$1014 \quad$ Evol. 31, 1929-1936.

1015 R Core Team, 2015. R: A language and environment for statistical computing.

1016 Rambaut, A., Suchard, M.A., Xie, W., Drummond, A.J., 2014. Tracer.

1017 Reid, N., Hird, S., Schulte-Hostedde, A., Sullivan, J., 2010. Examination of nuclear loci 1018 across a zone of mitochondrial introgression between Tamias ruficaudus and $T$. 1019 amoenus. J. Mammal. 91, 1389-1400. doi:10.1644/09-MAMM-A-082.1.Key

1020 Rickart, E.A., 1987. Spermophilus townsendii. Mamm. Species 268, 1-6.

$1021 \quad$ doi:http://dx.doi.org/10.2307/0.268.1

1022 Rickart, E.A., Hoffmann, R.S., Rosenfield, M., 1985. Karyotype of Spermophilus 1023 townsendii artemesiae (Rodentia:Sciuridae) and chromosomal variation in the Spermophilus townsendii complex. Mamm. Chromosom. Newsl. 26, 94-102.

1025 Riddle, B.R., Jezkova, T., Hornsby, A.D., Matocq, M.D., 2014. Assembling the modern 1026 1027 Great Basin mammal biota: insights from molecular biogeography and the fossil record. J. Mammal. 95, 1107-1127. doi:10.1644/14-MAMM-S-064

1028 Robinson, J.W., Hoffmann, R.S., 1975. Geographical and interspecific cranial variation 1029 in big-eared ground squirrels (Spermophilus): a multivariate study. Syst. Zool. 24, 1030 79-88. doi:10.1093/sysbio/24.1.79 
1031 Ronquist, F., Huelsenbeck, J.P., 2003. MrBayes 3: Bayesian phylogenetic inference $1032 \quad$ under mixed models. Bioinformatics 19, 1572-1574.

1033 doi:10.1093/bioinformatics/btg180

1034 Runck, A.M., Matocq, M.D., Cook, J.A., 2009. Historic hybridization and persistence of a 1035 novel mito-nuclear combination in red-backed voles (genus Myodes). BMC Evol.

$1036 \quad$ Biol. 9. doi:10.1186/1471-2148-9-114

1037 Scott, G.R., Hawkes, L.A., Frappell, P.B., Butler, P.J., Bishop, C.M., Milsom, W.K., 2015.

1038 How Bar-Headed Geese fly over the Himalayas. Physiology 30, 107-115.

1039 doi:10.1152/physiol.00050.2014

1040 Seehausen, O., 2004. Hybridization and adaptive radiation. Trends Ecol. Evol. 19, 1981041 207. doi:10.1016/j.tree.2004.01.003

1042 Seo, T.-K., 2008. Calculating bootstrap probabilities of phylogeny using multilocus 1043 sequence data. Mol. Biol. Evol. 25, 960-971. doi:10.1093/molbev/msn043

1044 Shen, Y.-Y., Liang, L., Zhu, Z.-H., Zhou, W.-P., Irwin, D.M., Zhang, Y.-P., 2010. Adaptive 1045 evolution of energy metabolism genes and the origin of flight in bats. Proc. Natl. 1046 Acad. Sci. U. S. A. 107, 8666-8671. doi:10.1073/pnas.0912613107

1047 Spiridonova, L.N., Chelomina, G.N., Tsuda, K., Yonekawa, H., Starikov, V.P., 2006.

1048 Genetic evidence of extensive introgression of short-tailed ground squirrel genes 1049 in a hybridization zone of Spermophilus major and S. erythrogenys, inferred from 1050 sequencing of the mtDNA cytochrome b gene. Russ. J. Genet. 42, 802-809.

1051 doi:10.1134/S1022795406070167 
1052 Staples, J.F., 2014. Metabolic suppression in mammalian hibernation: the role of 1053 mitochondria. J. Exp. Biol. 217, 2032-2036. doi:10.1242/jeb.092973

1054 Staples, J.F., Brown, J.C.L., 2008. Mitochondrial metabolism in hibernation and daily

1055 torpor: a review. J. Comp. Physiol. B 178, 811-827. doi:10.1007/s00360-008-

$1056 \quad 0282-8$

1057 Storz, J.F., Wheat, C.W., 2010. Integrating evolutionary and functional approaches to 1058 infer adaptation at specific loci. Evolution 64, 2489-2509. doi:10.1111/j.1558$1059 \quad 5646.2010 .01044 . x$

1060 Sullivan, J., Demboski, J.R., Bell, K.C., Hird, S., Sarver, B., Reid, N., Good, J.M., 2014. 1061 Divergence with gene flow within the recent chipmunk radiation (Tamias).

$1062 \quad$ Heredity $113,185-194$. doi:10.1038/hdy.2014.27

1063 Tamura, K., Stecher, G., Peterson, D., Filipski, A., Kumar, S., 2013. MEGA6: Molecular 1064 Evolutionary Genetics Analysis version 6.0. Molecular Biology and Evolution 30, $1065 \quad 2725-2729$.

1066 Thompson, C.W., Stangl, F.B., Bradley, R.D., 2015. Ancient hybridization and 1067 subsequent mitochondrial capture in ground squirrels (genus Ictidomys). Occas. 1068 Pap. Museum Texas Tech Univ. 331.

1069 Thorington, R.W., Koprowski, J.L., Steele, M.L., Whatton, J.F., 2012. Squirrels of the $1070 \quad$ World. The Johns Hopkins University Press, Baltimore.

1071 Toews, D.P.L., Brelsford, A., 2012. The biogeography of mitochondrial and nuclear 1072 discordance in animals. Mol. Ecol. 21, 3907-3930. doi:10.1111/j.1365$1073 \quad$ 294X.2012.05664.x 
1074 Toews, D.P.L., Mandic, M., Richards, J.G., Irwin, D.E., 2013. Migration, mitochondria, 1075 and the yellow-rumped warbler. Evolution 68, 241-255. doi:10.1111/evo.12260

1076 Tsvirka, M. V., Chelomina, G.N., Korablev, V.P., 2006. Genetic evidence of hybridization 1077 between paletailed Spermophilus pallidicauda Satunin, 1903 and Alashanic $S$. 1078 alaschanicus Büchner, 1888 ground squirrels in Mongolia. Russ. J. Genet. 42, 1079 421-428. doi:10.1134/S1022795406040090

1080 Wiens, J.J., Engstrom, T.N., Chippindale, P.T., 2006. Rapid diversification, incomplete 1081 isolation, and the "speciation clock" in North American salamanders (genus 1082 Plethodon): testing the hybrid swarm hypothesis of rapid radiation. Evolution 60, 1083 2585-2603. doi:10.1111/j.0014-3820.2006.tb01892.x

1084 Wilson, D.E., Reeder, D.M. (Eds.), 2005. Mammal Species of the World, 3rd ed. Johns $1085 \quad$ Hopkins University Press, Baltimore.

1086 Wilson, R.E., Peters, J.L., McCracken, K.G., 2013. Genetic and phenotypic divergence 1087 1088 between low- and high-altitude populations of two recently diverged Cinnamon Teal subspecies. Evolution 67, 170-184. doi:10.1111/j.1558-5646.2012.01740.x

1089 Yensen, E., Sherman, P.W., 1997. Spermophilus brunneus. Mamm. Species 560, 1-5. 1090 doi:http://dx.doi.org/10.2307/3504405

1091 Yensen, E., Sherman, P.W., 2003. Ground-dwelling Squirrels of the Pacific Northwest. 1092 U.S. Fish and Wildlife Service, U.S. Bureau of Land Management, Boise.

1093 Zelditch, M.L., Li, J., Tran, L.A.P., Swiderski, D.L., 2015. Relationships of diversity, 1094 disparity, and their evolutionary rates in squirrels (Sciuridae). Evolution 69, 1284$1095 \quad$ 1300. doi:10.1111/evo.12642 


\section{Figure Captions}

Figure 1. Geographic distribution of the big-eared species group of Urocitellus in the Palearctic (left) and Nearctic (right). Different species are indicated by numbers as follows: 1) $U$. undulatus, 2) U. parryii, 3) $U$. columbianus, 4) $U$. richardsonii, 5) $U$. beldingi, 6) $U$. armatus, and 7) $U$. elegans.

Figure 2. Geographic distribution of the small-eared species group of Urocitellus. Different species are indicated by different shapes. Subspecies are indicated by numbers as follows: 1) U. townsendii nancyae, 2) U. t. townsendii, 3) U. washingtoni, 4) $U$. brunneus brunneus, 5) $U$. b. endemicus, 6) $U$. canus canus, 7) $U$. c. vigilis, 8) $U$. mollis idahoensis, 9) U. m. artemesiae, 10) U. m. mollis. State abbreviations are $\mathrm{CA}=$ California, ID=Idaho, MT=Montana, NV=Nevada, OR=Oregon, UT=Utah, $\mathrm{WA}=$ Washington. Major rivers are indicated by white text.

Figure 3. Maximum clade credibility phylogram of Urocitellus based on Bayesian partitioned analysis of mtDNA (CYTB and control region, 1662bp total). Nodes receiving $>0.95$ posterior probability (PP) support indicated with closed circles. Three poorlysupported internal nodes are labeled specifically to highlight interspecies relationships. Bars at right are colored to represent recovery of species monophyly (black) or nonmonophyly (gray). Sample locations (state/province) are indicated in underlined text at right of clades; all states in USA unless otherwise abbreviated (CAN=Canada, RUS=Russia, MON=Mongolia). Outgroups are Ammospermophilus leucurus and Otospermophilus beecheyi.

Figure 4. Maximum clade credibility phylogram of Urocitellus based on Bayesian analysis of partial von Willebrand's factor (VWF, 860bp). Nodes receiving $>0.95$ posterior probability (PP) support indicated with closed circles (as in Fig. 3). Bars at right are colored to represent species monophyly (black) or non-monophyly (gray). Outgroups as in Fig. 3.

Figure 5. Multidimensional scaling plot of Robinson-Foulds distances among gene tree topologies. Trees were selected randomly from gene tree posterior distributions $(N=500$ per locus; 3000 total).

Figure 6. Species tree reconstructions of Urocitellus using 3 different methods ( ${ }^{\star}$ BEAST, STAR, MP-EST) based on all loci (top row) and nuclear loci only (bottom row). Trees are maximum clade credibility cladograms (i.e., w/o branch lengths). Outgroups as in Fig. 3.

Figure 7. Haplotype network based on mtDNA CYTB (1140bp; sequences compiled from this and previous studies). Taxa included are $U$. parryii parryii, $U$. parryii kennicottii, $U$. elegans elegans and $U$. richardsonii. Labels indicate the state/province of collection $(\mathrm{AK}=\mathrm{Alaska}, \mathrm{CO}=$ Colorado, $\mathrm{MT}=$ Montana, $\mathrm{WY}=$ Wyoming; $\mathrm{AB}=\mathrm{Alberta}, \mathrm{MB}=$ Manitoba, $\mathrm{NT}=$ Northwest Territories, NU=Nunavut, SK=Saskatchewan). Hash marks represent single mutations. Number of individuals is proportional to the size of the circle (see legend).

Figure 8. Geographic distribution of the entire PRE clade with major mtDNA clades indicated by color/shading. Subspecies of $U$. elegans and $U$. richardonii are indicated with text, and subspecies of $U$. parryii are numbered as follows: 1) U. p. ablusus, 2) U. p. 
kennicottii, 3) U. p. kodiacensis, 4) U. p. leucostictus, 5) U. p. lyratus, 6) U. p. nebulicola, 7) U. p. osgoodi, 8) U. p. parryii, 9) U. p. plesius, 10) U. p. stejnegeri. 

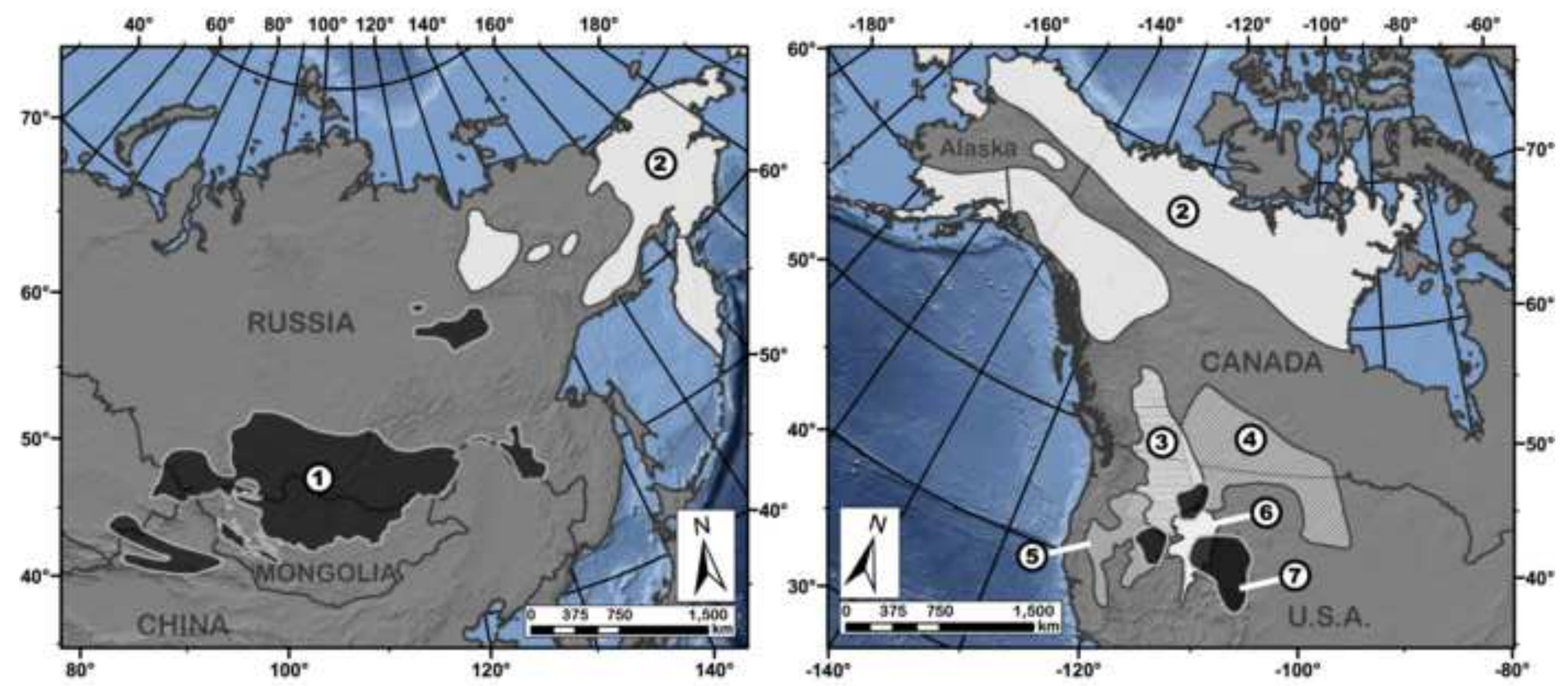


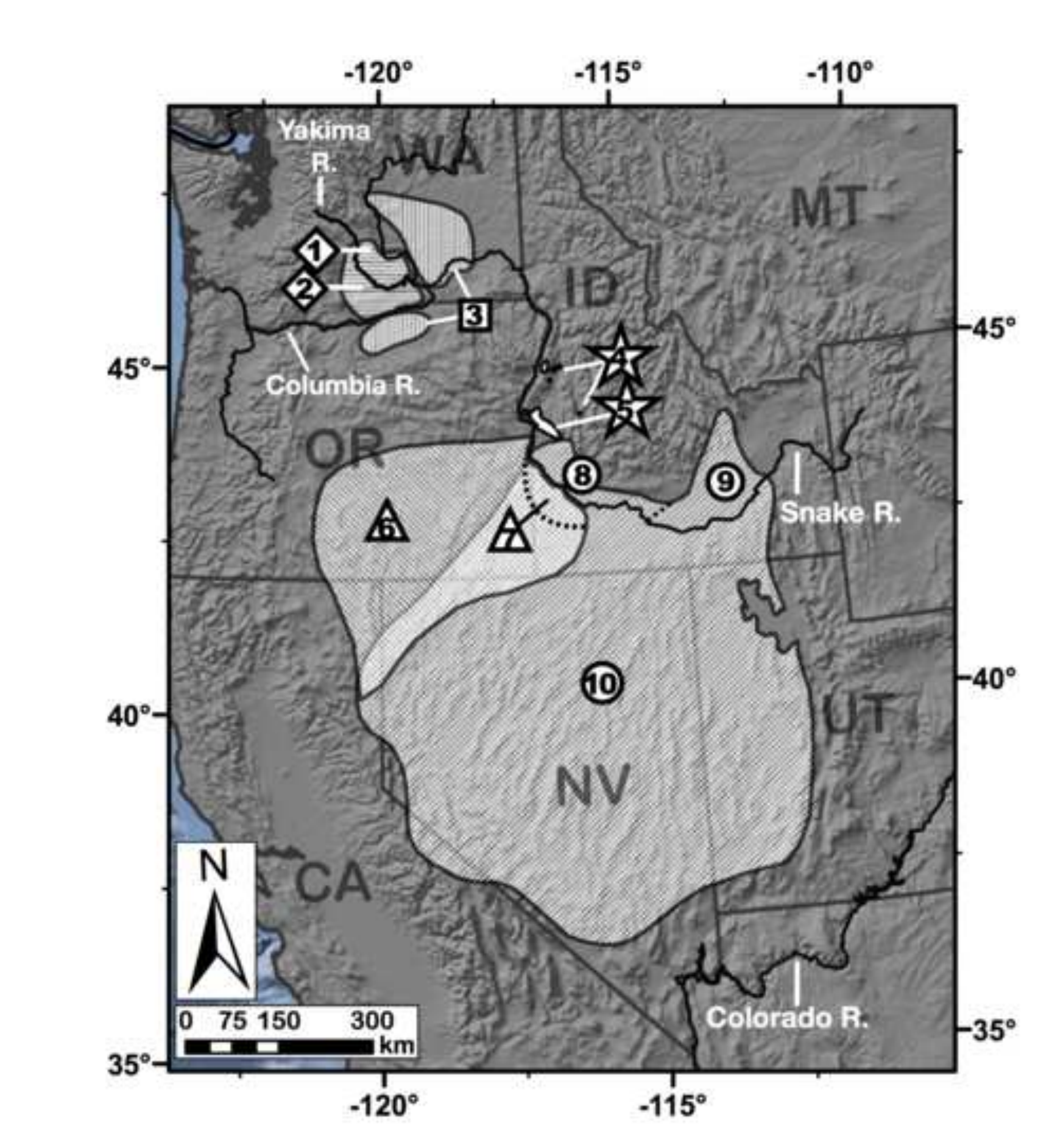

Figure 2

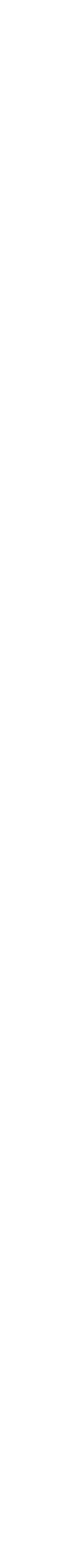

2

Figure 2

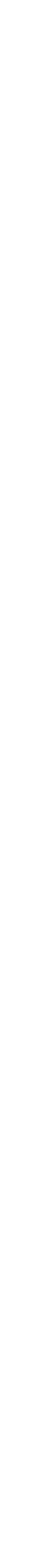

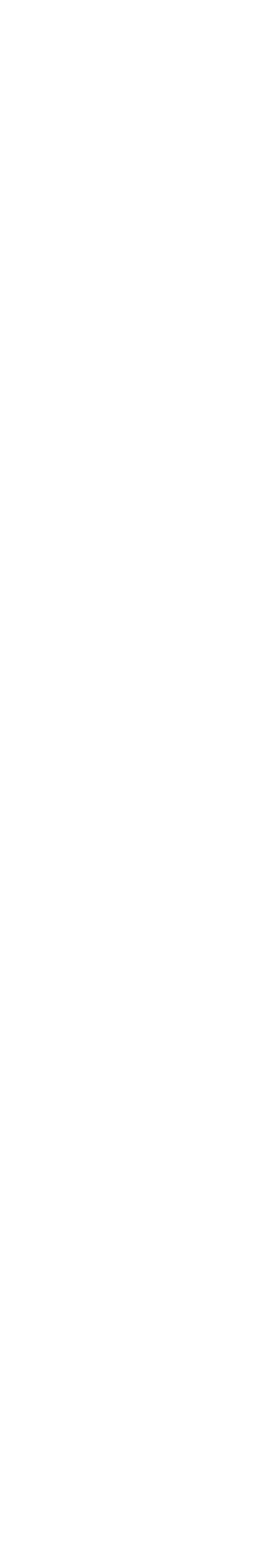

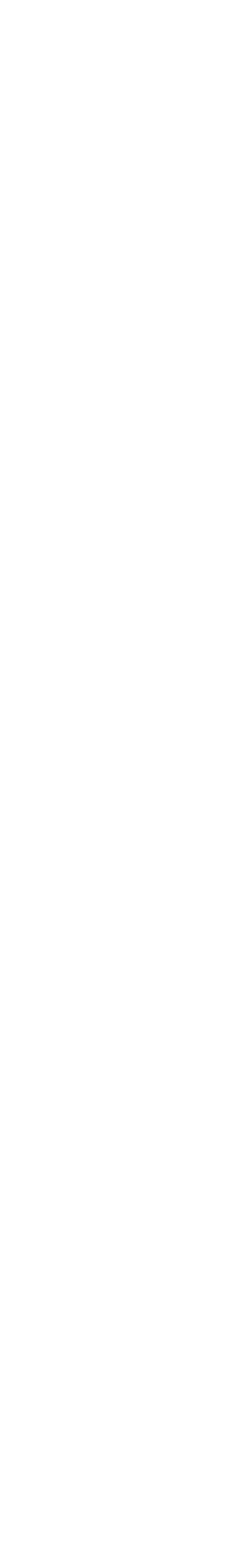


Figure 3

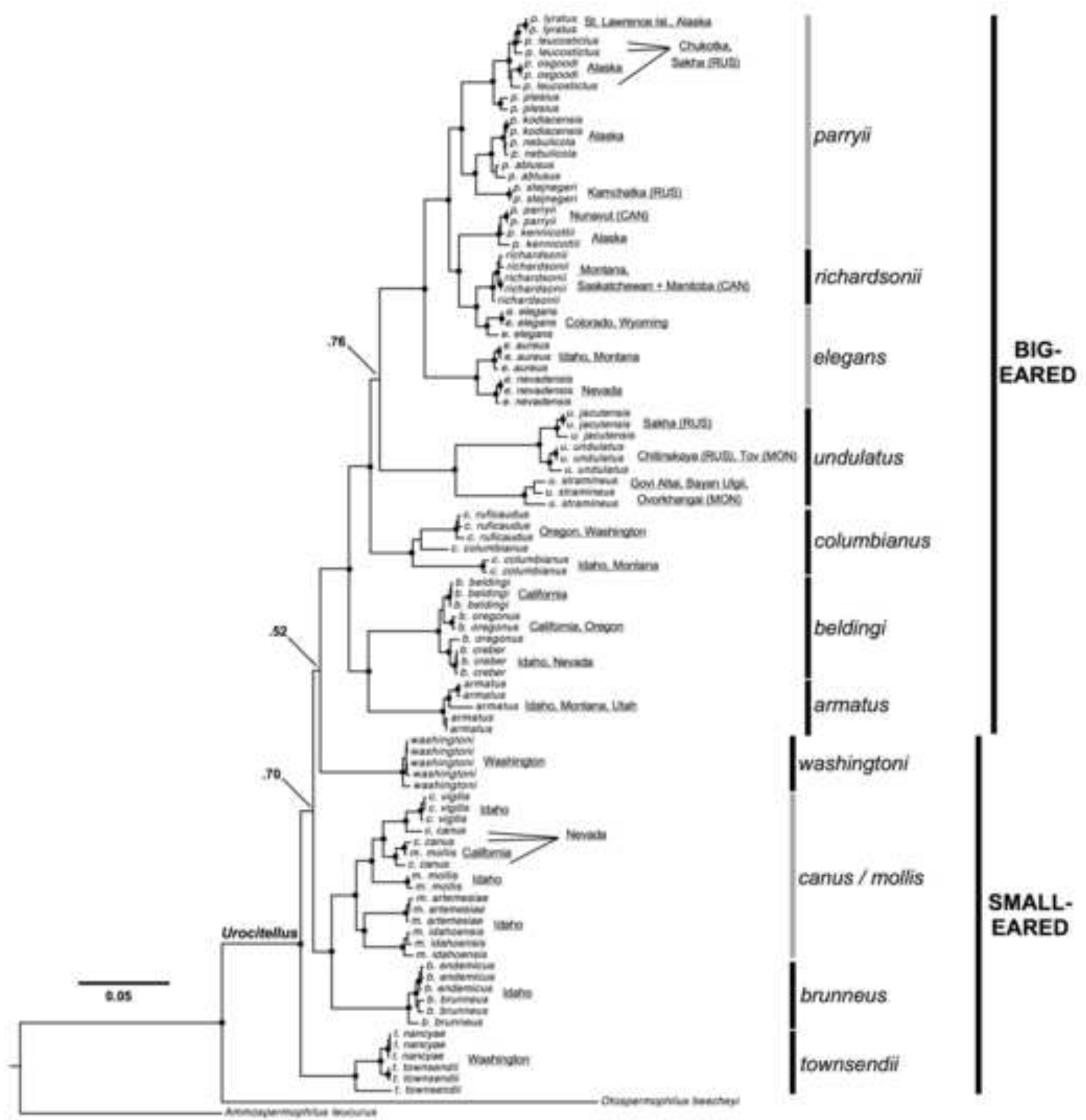

-s mova

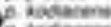

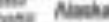

richardsonii

elegans

EARED

SMALL.

EARED

fownsendit 
Figure 4
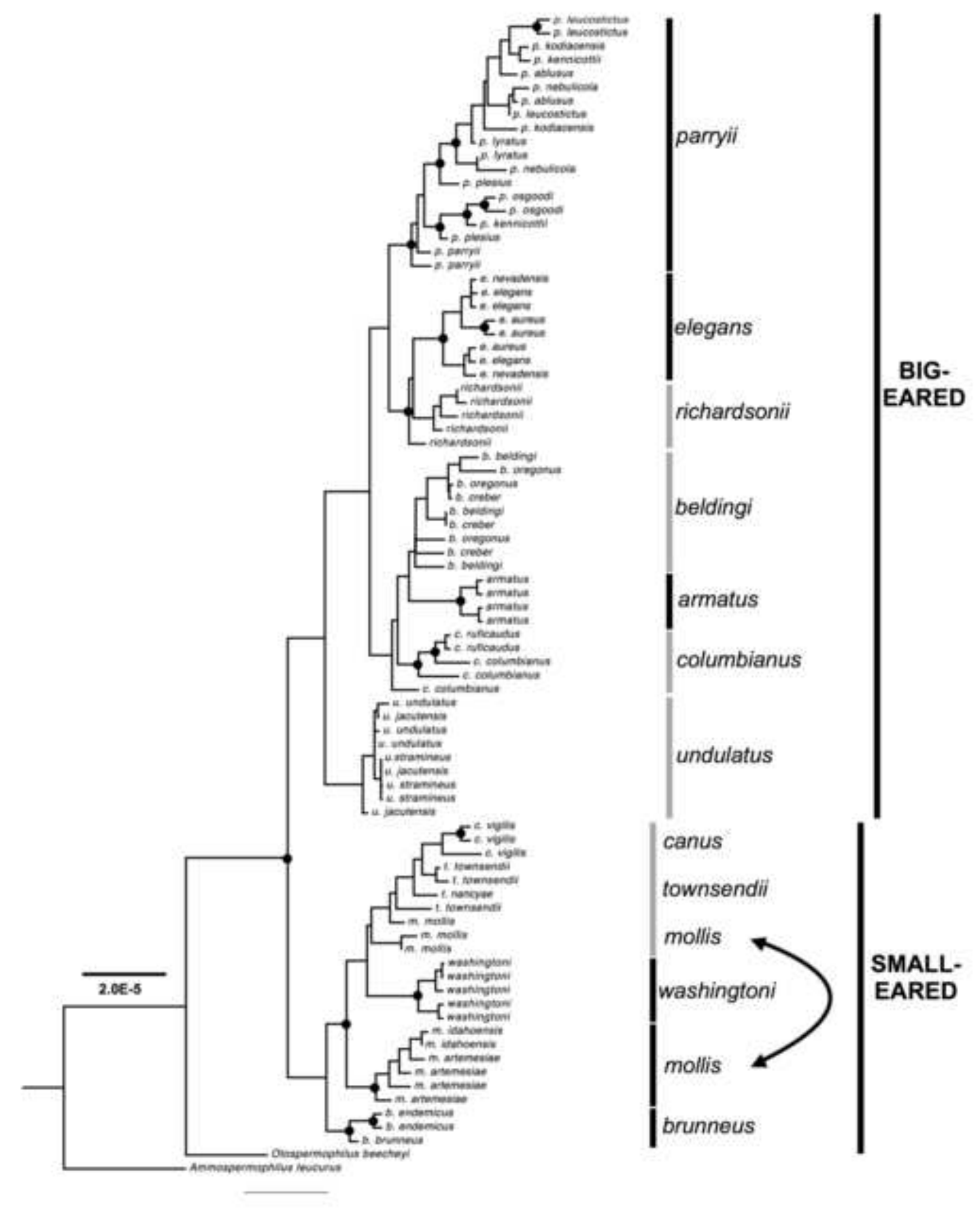


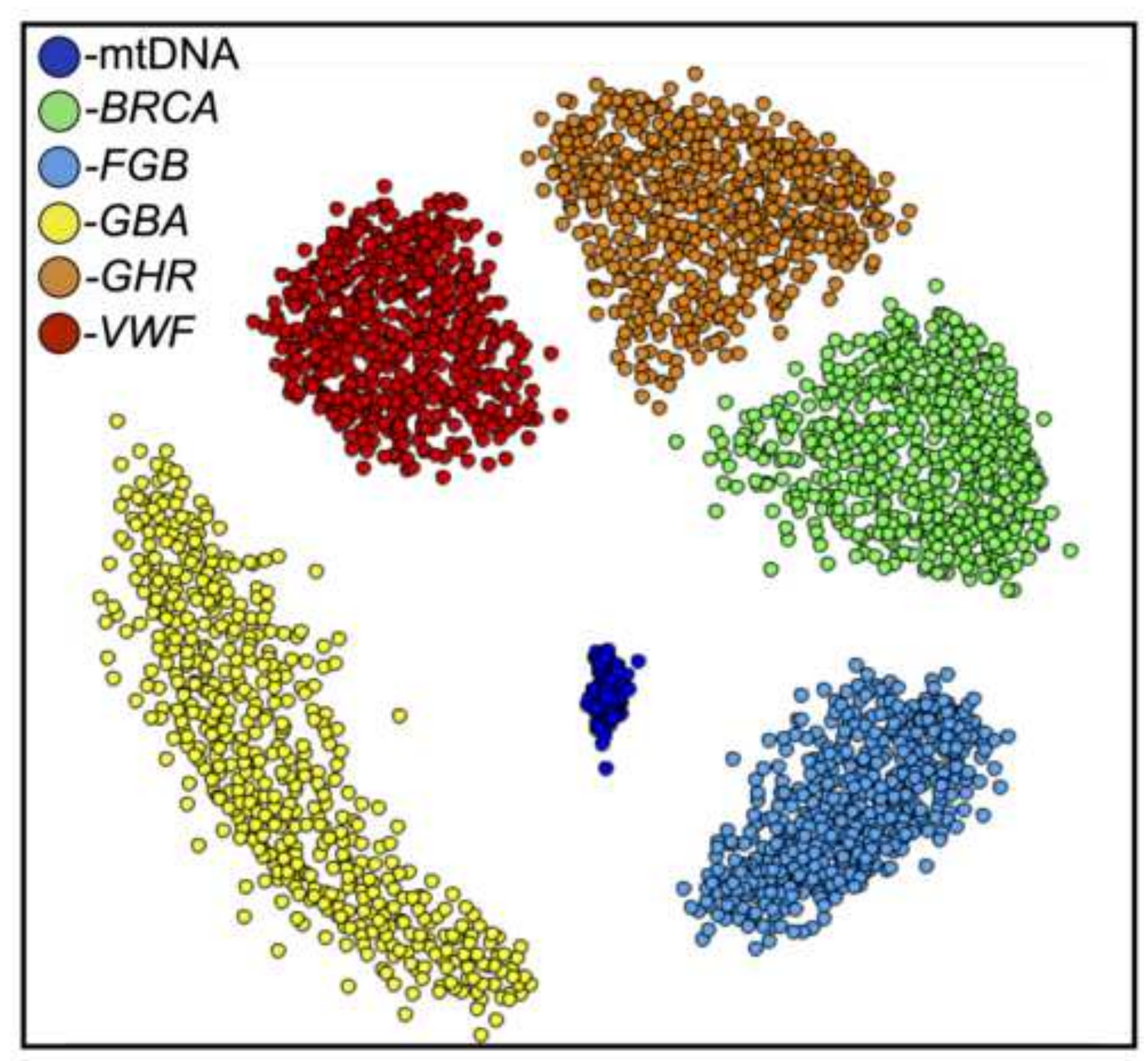



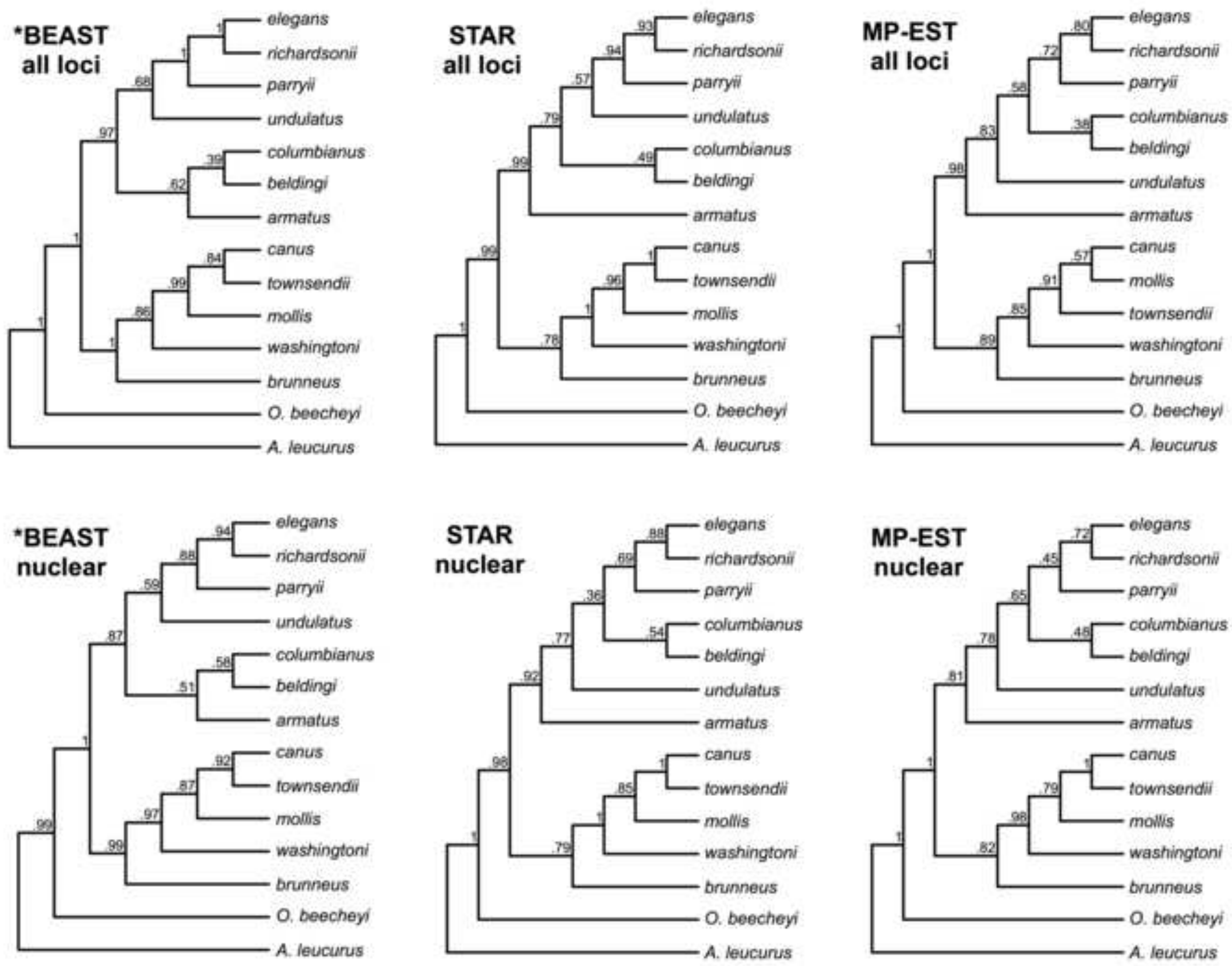


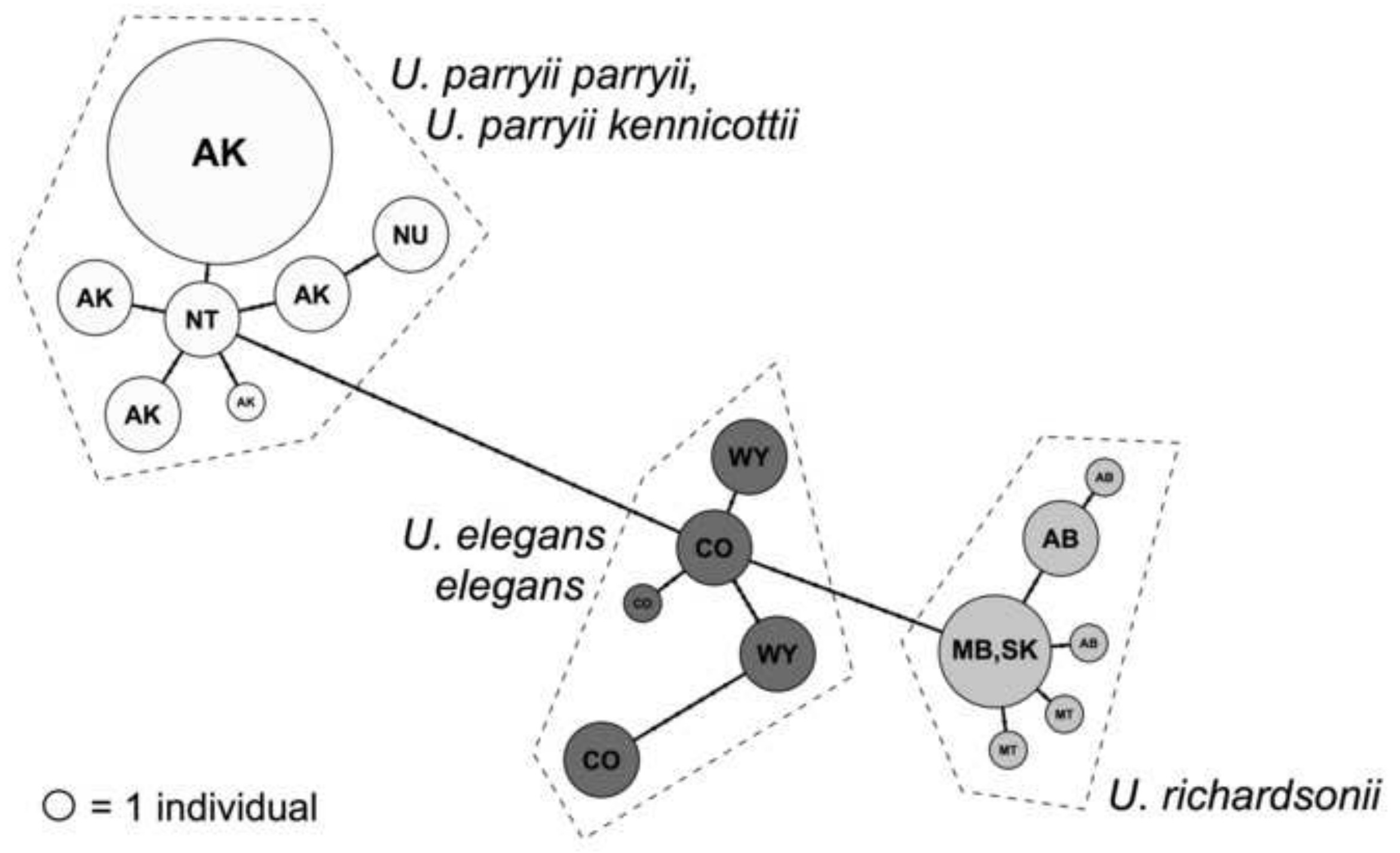




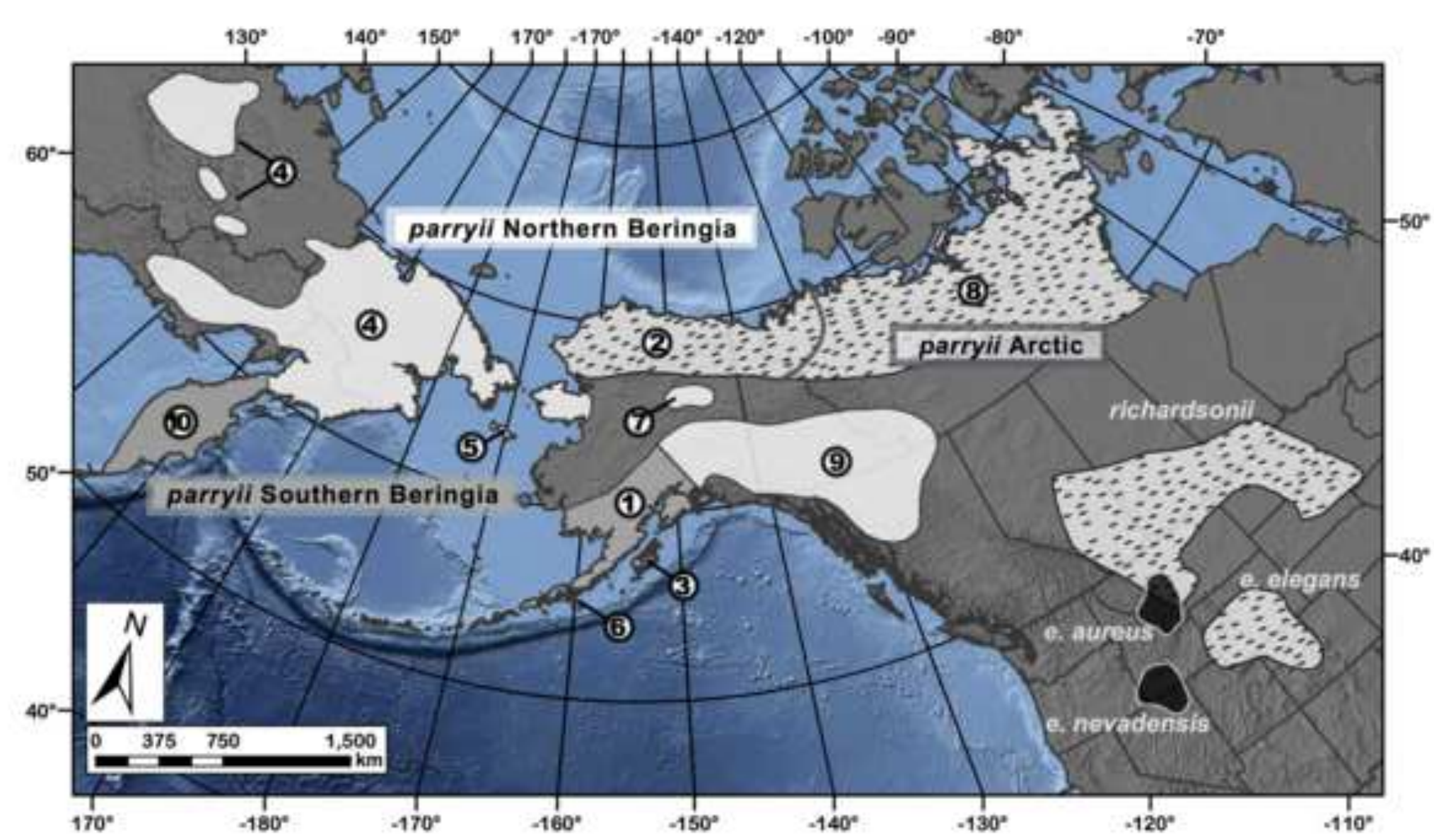




\begin{tabular}{|c|c|c|c|c|c|c|c|c|c|c|}
\hline Hypothesis & Basis & mtDNA & $V W F$ & $B R C A$ & $F G B$ & $G B A$ & GHR & "BEAST & STAR & $\begin{array}{l}\text { MP- } \\
\text { EST }\end{array}$ \\
\hline $\begin{array}{l}\text { big-eared } \\
\text { monophyly }\end{array}$ & $\begin{array}{l}\text { K - Nadler } 1966 \\
\text { K - Nadler } 1984\end{array}$ & $Y$ & $\mathrm{~N}$ & $\mathrm{~N}$ & $\mathrm{~N}$ & $\mathrm{~N}$ & $\mathrm{~N}$ & $\mathrm{Y} / \mathrm{N}$ & $\mathrm{Y} / \mathrm{N}$ & $\mathrm{Y} / \mathrm{N}$ \\
\hline $\begin{array}{l}\text { small-eared } \\
\text { monophyly }\end{array}$ & $\begin{array}{l}\text { K- Nadler } 1966 \\
\text { mtDNA - Harrison } \\
\text { et al. } 2003\end{array}$ & $\mathrm{~N}$ & $\mathrm{~N}$ & $\mathrm{~N}$ & $\mathrm{~N}$ & $\mathrm{~N}$ & $\mathrm{~N}$ & $\mathrm{Y} / \mathrm{Y}$ & $\mathrm{N} / \mathrm{N}$ & $\mathrm{N} / \mathrm{N}$ \\
\hline $\begin{array}{l}\text { "townsendii } \\
\text { complex" } \\
\text { monophyly }\end{array}$ & $\begin{array}{l}\text { M - Howell } 1938 \\
\text { K - Nadaler 1982 } \\
\text { K - Nadder 1984 }\end{array}$ & $\mathrm{N}$ & $\mathrm{N}$ & $\mathrm{N}$ & $\mathrm{N}$ & $\mathrm{N}$ & $\mathrm{N}$ & $\mathrm{Y} / \mathrm{N}$ & $\mathrm{Y} / \mathrm{N}$ & $\mathrm{N} / \mathrm{N}$ \\
\hline $\begin{array}{c}\text { elegans } \\
\text { monophyly }\end{array}$ & $\begin{array}{l}\text { M- Robinson and } \\
\text { Hoffmann } 1975 \\
\text { K - Nadder 1966 } \\
\text { K - Nadler 1971 } 1971\end{array}$ & $\mathrm{~N}$ & $Y$ & $Y$ & $\mathrm{~N}$ & $Y$ & $Y$ & - & $\begin{array}{lll}- & \text { r }\end{array}$ & - \\
\hline $\begin{array}{c}\text { parryii } \\
\text { monophyly }\end{array}$ & $\begin{array}{l}\text { M- Robiinson and } \\
\text { Hoffmann } 1975 \\
\text { K - Nadler r } 1966 \\
\text { K- Nadder } 1984\end{array}$ & $\mathrm{~N}$ & $Y$ & $Y$ & Y & $\mathrm{N}$ & $Y$ & - & - & - \\
\hline $\begin{array}{c}\text { mollis } \\
\text { monophyly }\end{array}$ & $\begin{array}{l}\text { M - Davis } 1939 \\
\text { K - Rickart } 1985\end{array}$ & $\mathrm{~N}$ & $\mathrm{~N}$ & $\mathrm{~N}$ & $\mathrm{~N}$ & $\mathrm{~N}$ & $\mathrm{~N}$ & - & $\begin{array}{lll}- & \text { r }\end{array}$ & - \\
\hline
\end{tabular}

Table 1. Phylogenetic hypotheses tested in this study (column 1) and their basis (column 2; $\mathrm{M}=$ morphology, $\mathrm{K}=$ karyotypic, $\mathrm{mtDNA}=$ mitochondrial $\mathrm{DNA}$; references are those most relevant to the hypotheses presented). Columns 3-11 list the results of hypothesis tests using single gene trees (mtDNA, 5 nuclear) as well as species trees reconstructed using 3 different methods. Species tree results are in the format: all loci/nuclear loci only. The "townsendii complex" consists of $U$. canus, $U$. mollis, and $U$. townsendii. See text for further details. 


\begin{tabular}{|c|c|c|c|}
\hline $\begin{array}{c}\text { Species } \\
\text { Comparison }\end{array}$ & $\begin{array}{c}\text { Minimum } \\
\text { Genetic } \\
\text { Distance }\end{array}$ & $P$ & $\begin{array}{c}\text { Percentage of } \\
\text { Subspecific } \\
\text { Comparisons } \\
\text { Significant }\end{array}$ \\
\hline U. elegans - U. richardsonii & 0.0114 & 0.06 & $1 / 3(33 \%)$ \\
\hline U. parryii- U. richardsonii & 0.0254 & 0.06 & $2 / 10(20 \%)$ \\
\hline U. parryii- U. elegans & 0.0254 & 0.09 & $2 / 30(6 \%)$ \\
\hline U. mollis - U. beldingi & 0.0666 & 0.04 & $6 / 9(66 \%)$ \\
\hline U. canus - U. beldingi & 0.0710 & 0.07 & $3 / 3(100 \%)$ \\
\hline
\end{tabular}

Table 2. Species comparisons from posterior predictive checking in JML recovered as significant at the $P=0.1$ level. Listed are minimum empirical genetic distances found for samples within each significant species comparison and the exact significance level. The final column is a tabulation of the percentage of all possible subspecies combinations within each species comparison for which significance was found. 


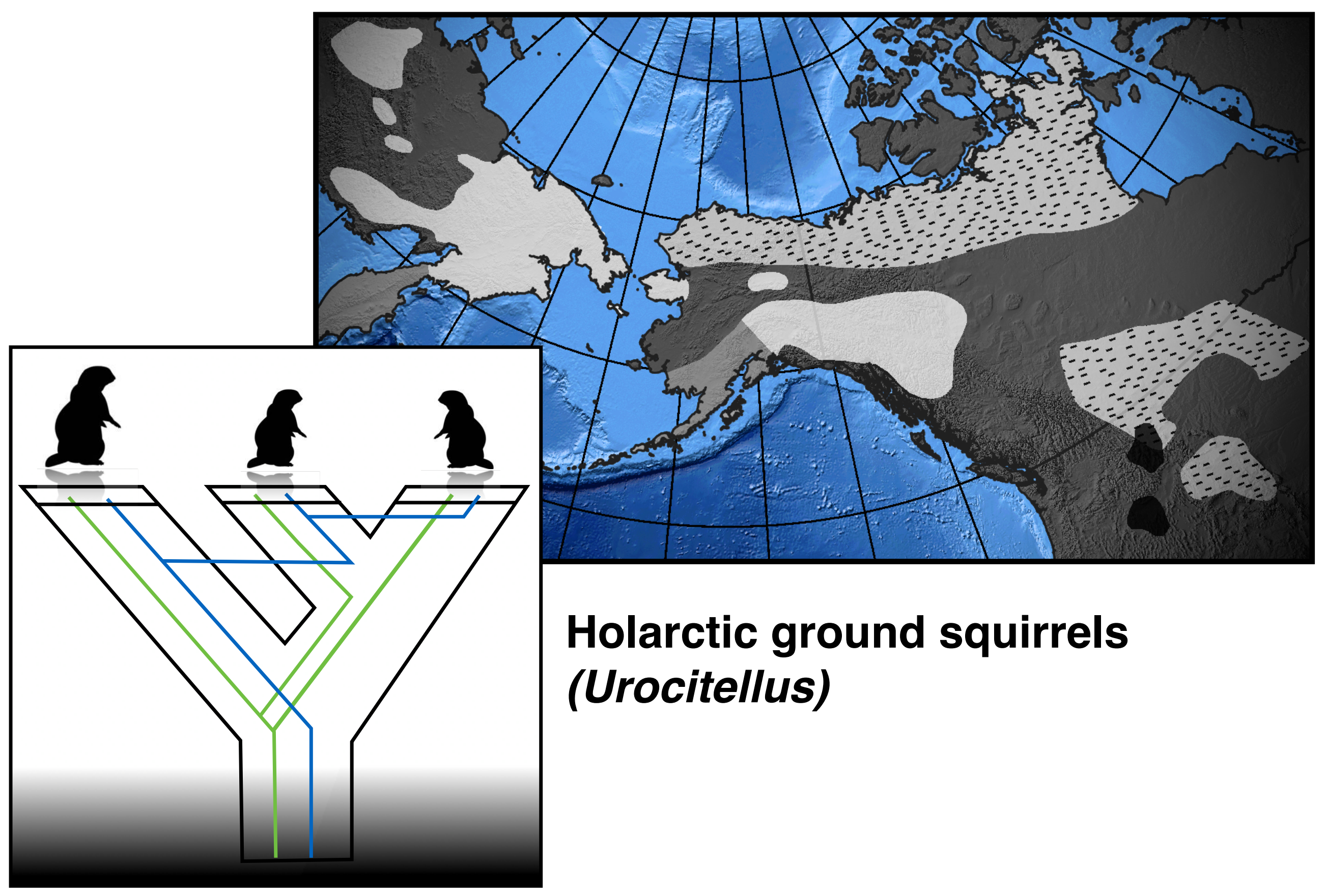

